Purdue University Purdue e-Pubs

2018

\title{
A Validated Time-Stepping Analytical Model for 3D Transient Vapor Chamber Transport
}

G. Patankar

Purdue University

J.A. Weibel

Purdue University, jaweibel@purdue.edu

S V. Garimella

Purdue University, sureshg@purdue.edu

Follow this and additional works at: http://docs.lib.purdue.edu/coolingpubs

Patankar, G.; Weibel, J. A.; and Garimella, S V., "A Validated Time-Stepping Analytical Model for 3D Transient Vapor Chamber Transport" (2018). CTRC Research Publications. Paper 322.

http://dx.doi.org/https://doi.org/10.1016/j.ijheatmasstransfer.2017.11.135

This document has been made available through Purdue e-Pubs, a service of the Purdue University Libraries. Please contact epubs@purdue.edu for additional information. 


\title{
A Validated Time-Stepping Analytical Model for 3D Transient Vapor Chamber Transport
}

\author{
Gaurav Patankar, Justin A. Weibel and Suresh V. Garimella* \\ Cooling Technologies Research Center, an NSF I/UCRC \\ School of Mechanical Engineering, Purdue University \\ 585 Purdue Mall, West Lafayette, IN 47907 USA
}

\begin{abstract}
Advances in the computational performance of electronic devices have created a clear need for improved methods of passive thermal management. This has led to renewed interest in the use of vapor chambers as heat spreaders in applications ranging from mobile devices to highperformance-computing and power electronics systems. While there has been significant effort to develop vapor chambers for these applications, their designs have largely relied on steady-state analyses and performance prediction. In many applications, however, the heat load is inherently transient in nature. Heat spreader design must consider transient performance in response to these use-case scenarios. While detailed numerical models of transient vapor chamber operation have been developed, a transient modeling approach with low computational cost is needed for parametric study and quick assessment of vapor chamber performance in system-level models.

In the current work, a low-cost, transient vapor chamber model is developed targeting the geometries and operating conditions typical of thermal management applications. The model considers mass, momentum, and energy transport in the vapor chamber wall, wick, and vapor core as well as phase change at the wick-vapor interface. The governing equations are simplified to a system of first-order differential equations based on a scaling analysis and assuming a functional form for the temperature profile along the thickness dimension. The errors in the

*Corresponding author: Tel. 7654945621 ; sureshg@purdue.edu
\end{abstract}


temperature and pressure fields due to these simplifying assumptions are estimated for a wide range of operating conditions. These estimates indicate low errors in the model predictions over the range considered. For two example cases, the model predictions are compared to a finitevolume-based numerical model. Any deviation from the numerical model prediction is on the same order as the errors estimated based on the simplifying assumptions. The time-stepping analytical model is demonstrated to have a computational cost reduction of three to four orders of magnitude compared to the finite-volume based model.

Keywords: vapor chamber, heat pipe, heat spreaders, transient, low-cost modeling

\section{Nomenclature}

$\underset{\sim}{A}, \underset{\sim}{B} \quad$ matrix containing thermophysical and geometric properties

$\underline{b}_{l k} \quad$ coefficients of $2 \mathrm{D}$ Fourier series $\left[\mathrm{K} \mathrm{s}^{-1}\right]$

$\underline{C} \quad$ vector source term $\left[\mathrm{K} \mathrm{s}^{-1}\right]$

$\underline{a}_{l k}, c_{l k} \quad$ coefficients of 2D Fourier series $[\mathrm{K}]$

$C N_{C C} \quad$ condition number for linearizing the Clausius-Clapeyron equation

$C N_{\text {conv }} \quad$ condition number for assuming negligible convection in the momentum equation

in the vapor core

$C N_{T} \quad$ condition number for assuming negligible temperature difference across the thicknesses of the wall and the wick on the evaporator side

$d_{\text {sum }, l k}, d_{\text {diff }, l k} \quad$ coefficients of 2D Fourier series $[\mathrm{Pa}]$

$d_{p} \quad$ wick particle diameter $[\mathrm{m}]$

$\rho C_{p} \quad$ volumetric specific heat capacity $\left[\mathrm{J} \mathrm{kg}^{-1} \mathrm{~K}^{-1}\right]$ 


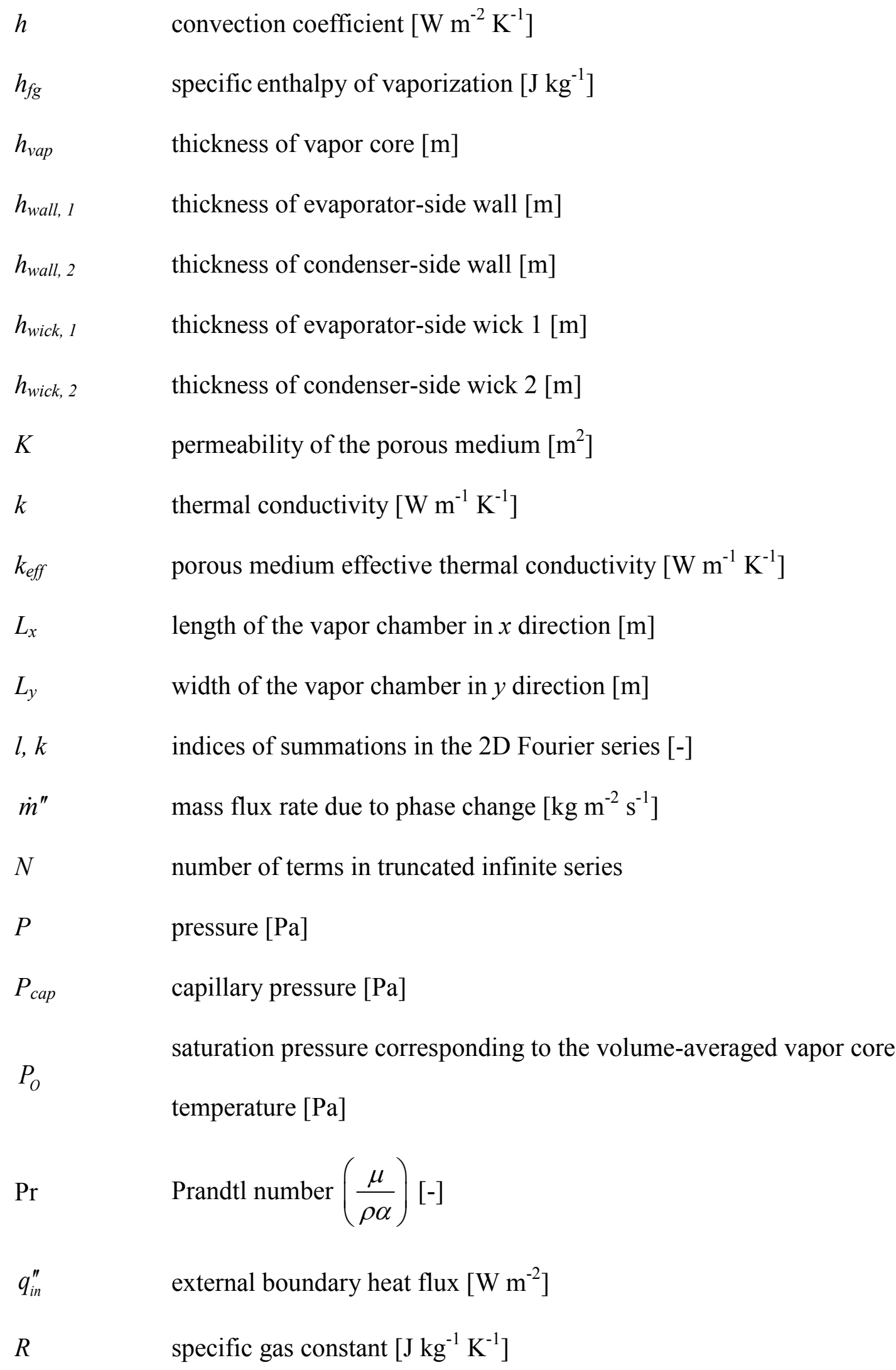




$\begin{array}{ll}\text { Re } & \text { Reynolds number }\left(\frac{\rho U L}{\mu}\right)[-] \\ T & \text { temperature }[\mathrm{K}] \\ \bar{T} & z \text {-averaged temperature }[\mathrm{K} \\ T_{\text {sat }} & \text { saturation temperature }[\mathrm{K}] \\ T_{\infty} & \text { ambient temperature }[\mathrm{K}] \\ t & \text { time [s] } \\ u & x \text {-component of velocity }\left[\mathrm{m} \mathrm{s}^{-1}\right] \\ \vec{V} & \left.\quad \text { velocity vector [m s }{ }^{-1}\right] \\ v & y \text {-component of velocity }\left[\mathrm{m} \mathrm{s}^{-1}\right] \\ w & z \text {-component of velocity }\left[\mathrm{m} \mathrm{s}^{-1}\right] \\ x & x \text {-coordinate (length) direction [m] } \\ y & y \text {-coordinate (width) direction [m] } \\ z & z \text {-coordinate (thickness) direction [m] }\end{array}$

\section{Greek}

$\alpha$ thermal diffusivity $\left(k_{e f f} /\left(\rho C_{p}\right)_{e f f}\right)\left[\mathrm{m}^{2} \mathrm{~s}^{-1}\right]$ surface tension $[\mathrm{Pa} \mathrm{s}]$

$\varepsilon_{C C} \quad$ relative error in the pressure field due to linearization of the Clausius-Clapeyron equation

$\varepsilon_{\text {conv }} \quad$ relative error in the pressure field due to neglecting convection in the momentum equation in the vapor core

$\varepsilon_{T} \quad$ relative error in the temperature field due to neglecting temperature difference 
across the thicknesses of the wall and the wick on the evaporator side vector of temperature field variables $[\mathrm{K}]$

$\lambda$ constant $\left(\frac{h_{f g} P_{O}}{R\left(T_{\text {sat }}^{2}\right)_{\text {mean }}}\right)\left[\mathrm{Pa} \mathrm{K}^{-1}\right]$

$\mu$ viscosity [Pa s] density $\left[\mathrm{kg} \mathrm{m}^{-3}\right]$

$\sigma$ accommodation coefficient [-]

$\varphi$ constant $\left(\frac{2 \sigma}{2-\sigma} \frac{h_{f g} \rho_{\text {vap }}}{\left(T_{\text {vap }}^{1.5}\right)_{\text {mean }}}\left(\frac{1}{2 \pi R}\right)^{0.5}\right)\left[\mathrm{kg} \mathrm{m}^{-2} \mathrm{~s}^{-1} \mathrm{~K}^{-1}\right]$

porosity [-]

\section{Subscript}

int

wick-vapor interface

sum

wick 1 plus wick 2

diff

wick 1 minus wick 2

vap

corresponding to the vapor core

wall

corresponding to the wall

wick

corresponding to the wick

$x$

along $x$ coordinate direction

$y$

along $y$ coordinate direction

$z$

along $z$ coordinate direction

1

corresponding to the evaporator side

corresponding to the condenser side 


\section{Superscript}

$n$

time step

0

initial condition

\section{Vector notation}

$\begin{array}{ll}- & \text { Vector } \\ \sim & \text { Matrix }\end{array}$




\section{Introduction}

A vapor chamber passively spreads heat from a small heat source to a larger surface. The sealed chamber is typically lined on the inner surface with a porous wick material and has a hollow central core; the device is charged with a working fluid that is held in the wick as liquid and vaporizes into the core. Operation of the vapor chamber is illustrated in Figure 1. Heat input to the vapor chamber causes localized vapor generation at the wick-vapor interface, which spreads through the core. As vapor condenses at the colder wick-vapor interface, the heat released is conducted across the condenser-side wick and the wall to the heat rejection surface. Condensed liquid is pumped back to the evaporator in the porous wick via capillary forces, enabling continuous passive operation.

Vapor chambers and heat pipes are used in the thermal packaging of electronic components as integrated heat spreaders for a variety of applications. The heat flux dissipated ranges from $<$ $10 \mathrm{~W} / \mathrm{cm}^{2}$ for applications such as portable electronics [1] to $>500 \mathrm{~W} / \mathrm{cm}^{2}$ for cooling of radar power amplifiers and high-performance computing systems [2]. Common among these applications is the need for thin, compact heat spreaders that accommodate transient heat loads. For example, mobile electronic devices require heat spreaders of $<1 \mathrm{~mm}$ thickness and experience highly transient operation; idle periods of low heat generation are intermixed with shorter pulses of high-power operations (e.g., video recording or calling). Previous work in designing vapor chambers for mobile devices has been limited to a consideration of steady-state operation [3]. Evaluation of vapor chambers for mobile devices and other applications will require transport models capable of efficiently computing the temperature field for transient boundary conditions and thin form factors. 
Existing vapor chamber transport models introduce a range of complexities that typically represent a compromise between computational cost and fidelity. Discretized numerical models are capable of simulating the transient behavior of complex vapor chamber geometries under different operating conditions. Such models are only limited by assumptions inherent in the governing equations used to represent the transport mechanisms. Vadakkan et al. [4] and Ranjan et al. $[5,6]$ developed a finite-volume-based numerical model to solve the mass, momentum, and energy transport equations in the wall, wick, and vapor core of the vapor chamber, coupled with phase change at the wick-vapor interfaces. A model solving the same governing equations using the finite-volume method was developed by Famouri et al. [7] using cylindrical coordinates to model the behavior of heat pipes. Harmand et al. [8] developed a transient 3D finite-difference based numerical model for vapor chambers that solves governing equations which are simplified by assuming control volumes that span the thickness of the wick and the vapor-core separately. However, such numerical models have a relatively high computational cost incurred in iteratively solving the discretized nonlinear governing equations, especially for vapor chamber geometries with high aspect ratios, which require a large number of mesh elements with small cell sizes dictated by the thinnest dimension. For example, Patankar et al. [3] used a numerical vapor chamber model to analyze the steady-state performance of ultra-thin vapor chambers for mobile thermal management applications; due to the large computational cost, a steady-state-seeking solution procedure had to be adopted to bypass the physical transient behavior. Such numerical models are best suited to single-point evaluation of single device designs. They are, however, not practical for simulating a large number of cases covering a wide range of parameters.

Lower cost computational models for vapor chambers and heat pipes have also been developed in the literature, and they solve simplified governing equations analytically. For 
steady-state behavior, models are readily available for all levels of dimensionality. Prasher [9] and Yadavalli et al. [10] developed a 1D resistance-network-based model that predicts the steady-state temperature drop by assigning thermal resistances to each primary heat transport pathway in the heat pipe. Aghvami and Faghri [11] and Lefevre and Lallemand [12] respectively developed analytical models for computing 2D and 3D steady-state temperature fields in vapor chambers with arbitrary heat inputs. However, there are few examples of low-cost transient models for vapor chamber behavior. Zhu and Vafai [13] developed an analytical model that computed the transient temperature variation along the length and thickness of a vapor chamber. But the model utilized symmetry in the geometry and boundary conditions and thus did not accommodate boundary conditions corresponding to heat spreading from multiple arbitrarily shaped and located hotspots. Thus, there is a need for a low-cost transient vapor chamber transport model that computes the $3 \mathrm{D}$ temperature fields in the vapor chamber when subjected to arbitrarily placed, localized transient heat inputs.

The current work develops a low-cost, semi-analytical model for transient vapor chamber operation. The model solves for mass, momentum, and energy transport in the vapor chamber wall, wick and vapor core, along with phase change at the wick-vapor interface. The model simplifies the governing equations to a set of linear differential equations, which are solved using Fourier series substitutions and implicit time-stepping. Multiple, arbitrarily shaped, time-varying heat inputs can be imposed on the evaporator-side of the vapor chamber, with a uniform convective boundary condition on the condenser side. The computational cost of the model is compared with that of a high-fidelity, finite-volume numerical model. 


\section{Model development}

\subsection{Geometry, governing equations, and boundary conditions}

The vapor chamber has a three-dimensional rectangular geometry; Figure 2 illustrates the wall, wick, and vapor core domains and their sizes in the $x, y$, and $z$ coordinate directions. The wall, wick and the vapor-core have dimensions of $L_{x}$ and $L_{y}$, respectively, in the $x$ and $y$ directions. The vapor chamber is subjected to multiple arbitrarily shaped and time-varying heat inputs on one of its faces $(z=0)$, while the other face $\left(\mathrm{z}=h_{\text {wall, } 1}+h_{\text {wick, } 1}+h_{\text {vap }}+h_{\text {wick }, 2}+h_{\text {wall }, 2}\right)$ is subjected to a uniform convective boundary condition. The lateral walls are insulated. The thickness of the walls and wick along the sides at $x=0, x=L_{x}, y=0$ and $y=L_{y}$ is assumed to be negligible.

The governing equations solved in the vapor chamber transport model are described below. The wick is assumed to be a homogeneous porous medium with its pores fully saturated by the working liquid; the model does not account for recession of liquid into the wick. Flow in the wick and vapor core is assumed to be laminar and incompressible. The governing equations for mass, momentum and energy transport are

$$
\begin{gathered}
\frac{\partial u}{\partial x}+\frac{\partial v}{\partial y}+\frac{\partial w}{\partial z}=0 \\
\rho \frac{\partial \vec{V}}{\partial t}+\rho\left(u \frac{\partial \vec{V}}{\partial x}+v \frac{\partial \vec{V}}{\partial y}+w \frac{\partial \vec{V}}{\partial z}\right) \\
=-\nabla(\phi P)+\mu\left(\frac{\partial^{2} \vec{V}}{\partial x^{2}}+\frac{\partial^{2} \vec{V}}{\partial y^{2}}+\frac{\partial^{2} \vec{V}}{\partial z^{2}}\right)-\frac{\mu \phi}{K} \vec{V} \\
\left(\rho C_{P}\right)_{e f f}\left(\frac{\partial T}{\partial t}\right)+\left(\rho C_{P}\right)_{l}\left(u \frac{\partial T}{\partial x}+v \frac{\partial T}{\partial y}+w \frac{\partial T}{\partial z}\right) \\
=k_{\text {eff }}\left(\frac{\partial^{2} T}{\partial x^{2}}+\frac{\partial^{2} T}{\partial y^{2}}+\frac{\partial^{2} T}{\partial z^{2}}\right)
\end{gathered}
$$


In the vapor core, the porosity $\phi$ is 1 and the permeability $K$ is $\infty$. For the wick, $k_{\text {eff }}$ is the effective conductivity of the porous medium. For the wall and vapor core, the effective conductivity is equal to the corresponding material thermal conductivity. For the wick and the vapor core, $\left(\rho C_{P}\right)_{l}$ is the fluid volumetric heat capacity, while for the wall, $\left(\rho C_{P}\right)_{l}$ is set to zero; $\left(\rho C_{P}\right)_{\text {eff }}$ is the effective volumetric heat capacity, and

for the wick, $\left(\rho C_{P}\right)_{e f f}=\phi\left(\rho C_{P}\right)_{l}+(1-\phi)\left(\rho C_{P}\right)_{s}$,

for the wall, $\left(\rho C_{P}\right)_{e f f}=\left(\rho C_{P}\right)_{\text {wall }}$, and

for the vapor core, $\left(\rho C_{P}\right)_{e f f}=\left(\rho C_{P}\right)_{v a p}$,

where $\left(\rho C_{P}\right)_{s}$ is the volumetric heat capacity of the solid material of the porous wick. All thermophysical properties are assumed to be constant at a given time instant.

The mass flux rate due to phase change at the wick-vapor interface is evaluated using the difference between the local interface temperature and the local vapor-core saturation temperature [14] as:

$$
\dot{m}^{\prime \prime}=\frac{2 \sigma}{2-\sigma} \frac{h_{f g} \rho_{\text {vap }}}{T_{\text {vap }}^{1.5}}\left(\frac{1}{2 \pi R}\right)^{0.5}\left(T_{i n t}-T_{\text {sat }}\right) .
$$

A positive value indicates evaporation, while a negative value indicates condensation. The value of $\sigma$ is chosen to be 0.03 [15]. The saturation temperature in the vapor core is computed using the Clausius-Clapeyron equation

$$
\frac{d P_{v a p}}{d T_{\text {sat }}}=\frac{h_{f g} P_{v a p}}{R T_{\text {sat }}^{2}} .
$$


The boundary conditions for the vapor core specify that there is no slip in velocity at the thermally insulated lateral sidewalls.

$$
\begin{aligned}
& \text { at } x=0, \quad u=v=w=0 ; \frac{\partial T}{\partial x}=0 \\
& \text { at } x=L_{x}, \quad u=v=w=0 ; \frac{\partial T}{\partial x}=0 \\
& \text { at } y=0, \quad u=v=w=0 ; \frac{\partial T}{\partial y}=0 \\
& \text { at } y=L_{y}, \quad u=v=w=0 ; \frac{\partial T}{\partial y}=0
\end{aligned}
$$

At the interfaces with the wick domain, the velocity has a no-slip condition and mass and energy are conserved across the interface (accounting for enthalpy of vaporization):

$$
\begin{gathered}
\text { at } z=h_{\text {wall }, 1}+h_{\text {wick }, 1}, \\
(\rho w)_{\text {wick }}=(\rho w)_{\text {vap }} ; \quad u=v=0 ; \\
\left(-k_{\text {eff }} \frac{\partial T}{\partial z}\right)_{\text {wick }}-\dot{m}_{1}^{\prime \prime} h_{f g}=\left(-k \frac{\partial T}{\partial z}\right)_{\text {vap }} \\
\text { at } z=h_{\text {wall }, 1}+h_{\text {wick }, 1}+h_{\text {vap }}, \\
(\rho w)_{\text {wick }}=(\rho w)_{\text {vap }} ; u=v=0 ; \\
\left(k_{\text {eff }} \frac{\partial T}{\partial z}\right)_{\text {wick }}-\dot{m}_{2}^{\prime \prime} h_{f g}=\left(k \frac{\partial T}{\partial z}\right)_{v a p}
\end{gathered}
$$

where $\dot{m}_{1}^{\prime \prime}$ is the evaporative mass flux rate at $z=h_{\text {wall }, 1}+h_{\text {wick }, 1}$ and $\dot{m}_{2}^{\prime \prime}$ is the value at $z=h_{\text {wall }, 1}+h_{\text {wick }, 1}+h_{\text {vap }}$. The wall and wick layers on the evaporator and condenser sides are indicated by the indices 1 and 2, respectively. The two walls, two wicks, and vapor core are termed as zones henceforth. The boundary conditions at the edges of both wicks are 


$$
\begin{aligned}
& \text { at } x=0, \quad w=0 ; \quad \frac{\partial T}{\partial x}=0 \\
& \text { at } x=L_{x}, \quad w=0 ; \quad \frac{\partial T}{\partial x}=0 \\
& \text { at } y=0, \quad w=0 ; \quad \frac{\partial T}{\partial y}=0 \\
& \text { at } y=L_{y}, \quad w=0 ; \quad \frac{\partial T}{\partial y}=0
\end{aligned}
$$

Flow of liquid between the two wicks is connected at the boundaries at $x$ and $y$ limits by imposing the conditions shown below.

$$
\begin{aligned}
& \text { at } x=0, u_{\text {wick }, 1}=-u_{\text {wick }, 2} ; P_{\text {wick }, 1}=P_{\text {wick }, 2} \\
& \text { at } x=L_{x}, u_{\text {wick }, 1}=-u_{\text {wick }, 2} ; P_{\text {wick }, 1}=P_{\text {wick }, 2} \\
& \text { at } y=0, v_{\text {wick }, 1}=-v_{\text {wick }, 2} ; P_{\text {wick }, 1}=P_{\text {wick }, 2} \\
& \text { at } y=L_{y}, v_{\text {wick }, 1}=-v_{\text {wick }, 2} ; P_{\text {wick }, 1}=P_{\text {wick }, 2}
\end{aligned}
$$

At the interfaces of the wicks with the wall and the vapor core, the velocity has a no-slip condition and energy is conserved: 


$$
\begin{aligned}
& \text { at } z=h_{\text {wall }, 1}, u=v=w=0 ; \\
& \left(-k \frac{\partial T}{\partial z}\right)_{\text {wall }}=\left(-k_{\text {eff }} \frac{\partial T}{\partial z}\right)_{\text {wick }} \\
& \text { at } z=h_{\text {wall }, 1}+h_{\text {wick }, 1}, \\
& (\rho w)_{\text {wick }}=(\rho w)_{\text {vap }} ; u=v=0 \text {; } \\
& \left(-k_{\text {eff }} \frac{\partial T}{\partial z}\right)_{\text {wick }}-\dot{m}_{1}^{\prime \prime} h_{f g}=\left(-k \frac{\partial T}{\partial z}\right)_{\text {vap }} \\
& \text { at } z=h_{\text {wall }, 1}+h_{\text {wick }, 1}+h_{\text {vap }} \text {, } \\
& (\rho w)_{\text {wick }}=(\rho w)_{\text {vap }} ; u=v=0 \text {; } \\
& \left(k_{e f f} \frac{\partial T}{\partial z}\right)_{\text {wick }}-\dot{m}_{2}^{\prime \prime} h_{f g}=\left(k \frac{\partial T}{\partial z}\right)_{\text {vap }} \\
& \text { at } z=h_{\text {wall_1 }}+h_{\text {wick_1 }}+h_{\text {vap }}+h_{\text {wick_2 } 2} \text {, } \\
& u=v=w=0 ;\left(-k \frac{\partial T}{\partial z}\right)_{\text {wall }}=\left(-k_{\text {eff }} \frac{\partial T}{\partial z}\right)_{\text {wick }}
\end{aligned}
$$

The lateral boundaries of the vapor chamber are insulated, which yields the following boundary conditions for both the walls:

$$
\begin{aligned}
& \text { at } x=0, \quad \frac{\partial T}{\partial x}=0 \\
& \text { at } x=L_{x}, \quad \frac{\partial T}{\partial x}=0 \\
& \text { at } y=0, \quad \frac{\partial T}{\partial y}=0 \\
& \text { at } y=L_{y}, \frac{\partial T}{\partial y}=0
\end{aligned}
$$

The vapor chamber walls receive heat input(s) at the $z=0$ surface, are exposed to a convective condition at the $z=h_{\text {wall }, 1}+h_{\text {wick }, 1}+h_{\text {vap }}+h_{\text {wick }, 2}+h_{\text {wall }, 2}$ surface, and energy is conserved at the wick interfaces: 


$$
\begin{gathered}
\text { at } z=0,\left(-k \frac{\partial T}{\partial z}\right)_{\text {wall }}=q_{\text {in }}^{\prime \prime}(x, y) \\
\text { at } z=h_{\text {wall }, 1},\left(-k \frac{\partial T}{\partial z}\right)_{\text {wall }}=\left(-k_{\text {eff }} \frac{\partial T}{\partial z}\right)_{\text {wick }} \\
\text { at } z=h_{\text {wall }, 1}+h_{\text {wick }, 1}+h_{\text {vap }}+h_{\text {wick }, 2}, \\
\left(-k \frac{\partial T}{\partial z}\right)_{\text {wall }}=\left(-k_{\text {eff }} \frac{\partial T}{\partial z}\right)_{\text {wick }} \\
\text { at } z=h_{\text {wall }, 1}+h_{\text {wick }, 1}+h_{\text {vap }}+h_{\text {wick }, 2}+h_{\text {wall }, 2}, \\
\left(-k \frac{\partial T}{\partial z}\right)_{\text {wall }}=h\left(T-T_{\infty}\right)
\end{gathered}
$$

\subsection{Scaling analysis}

To render the governing equations more amenable to analytical solution, assumptions regarding the scales of the variables are used to eliminate terms of comparatively low magnitude. The scales used are shown in Table 1. Time scales based on $z$-diffusion used for momentum transport in the wick and the vapor core are

$$
\begin{gathered}
\text { for wick 1, } \tau \sim \frac{\rho_{\text {wick }} h_{\text {wick }, 1}^{2}}{\mu_{\text {wick }}} \text {; for wick } 2, \tau \sim \frac{\rho_{\text {wick }} h_{\text {wick }, 2}^{2}}{\mu_{\text {wick }}} ; \\
\text { for vapor core, } \tau \sim \frac{\rho_{\text {vap }} h_{\text {vap }}{ }^{2}}{\mu_{\text {vap }}}
\end{gathered}
$$

The following assumptions are made regarding the scale variables in the vapor core and the wick. The thicknesses of the two wicks and the vapor core are assumed to be much smaller than the size of the vapor chamber in the $x$ and $y$ directions.

$$
\begin{aligned}
& h_{\text {vap }}<<L_{x}, h_{\text {wick }, 1}<<L_{x}, h_{\text {wick }, 2}<<L_{x}, \\
& h_{\text {vap }}<<L_{y}, h_{\text {wick }, 1}<<L_{y}, h_{\text {wick }, 2}<<L_{y}
\end{aligned}
$$


Based on this assumption, diffusion in the $x$ and $y$ directions in the momentum and energy equations for the vapor core and wicks is considered negligible compared to diffusion in the $z$ direction (in the respective equations and zones). Thus,

$$
\frac{\partial^{2}}{\partial x^{2}}<<\frac{\partial^{2}}{\partial z^{2}}, \frac{\partial^{2}}{\partial y^{2}}<<\frac{\partial^{2}}{\partial z^{2}}
$$

The following assumptions are made regarding flow in the vapor core and the wick:

$$
\begin{aligned}
& \left(\operatorname{Re}_{x, \text { vap }} \frac{h_{\text {vap }}^{2}}{L_{x}^{2}}\right) \ll<,\left(\operatorname{Re}_{x, \text { wick }} \frac{h_{\text {wick } 1}{ }^{2}}{L_{x}^{2}}\right) \ll<1, \\
& \left(\operatorname{Re}_{x, \text { wick } \_2} \frac{h_{\text {wick }, 2}{ }^{2}}{L_{x}^{2}}\right) \ll<,\left(\operatorname{Re}_{y, \text { vap }} \frac{h_{\text {vap }}{ }^{2}}{L_{y}{ }^{2}}\right) \ll<\text {, } \\
& \left(\operatorname{Re}_{y, \text { wick }-1} \frac{h_{\text {wick }, 1}{ }^{2}}{L_{y}{ }^{2}}\right) \ll 1,\left(\operatorname{Re}_{y, \text { wick } \_2} \frac{h_{\text {wick, } 2}{ }^{2}}{L_{y}{ }^{2}}\right) \ll<1
\end{aligned}
$$

Based on these assumptions, the convection terms in the momentum equation for the wicks and the vapor core are considered negligible compared to diffusion in the $z$ direction. Thus,

$$
\rho u \frac{\partial}{\partial x}<<\mu \frac{\partial^{2}}{\partial z^{2}}, \rho v \frac{\partial}{\partial y}<<\mu \frac{\partial^{2}}{\partial z^{2}}, \rho w \frac{\partial}{\partial z}<<\mu \frac{\partial^{2}}{\partial z^{2}}
$$

The assumptions made regarding energy transport in the wicks and the vapor core are: 


$$
\begin{aligned}
& \left(\operatorname{Pr}_{\text {vap }} \operatorname{Re}_{x, \text { vap }} \frac{h_{\text {vap }}{ }^{2}}{L_{x}{ }^{2}}\right) \ll<, \\
& \left(\operatorname{Pr}_{\text {wick }} \operatorname{Re}_{x, \text { wick }, 1} \frac{h_{\text {wick }, 1}{ }^{2}}{L_{x}{ }^{2}}\right) \ll<1, \\
& \left(\operatorname{Pr}_{\text {wick }} \operatorname{Re}_{x, \text { wick }, 2} \frac{h_{\text {wick }, 2}{ }^{2}}{L_{x}{ }^{2}}\right) \ll<1, \\
& \left(\operatorname{Pr}_{\text {vap }} \operatorname{Re}_{y, \text { vap }} \frac{h_{\text {vap }}{ }^{2}}{L_{y}{ }^{2}}\right) \ll<1, \\
& \left(\operatorname{Pr}_{\text {wick }} \operatorname{Re}_{y, \text { wick }, 1} \frac{h_{\text {wick }, 1}{ }^{2}}{L_{y}{ }^{2}}\right) \ll<1, \\
& \left(\operatorname{Pr}_{\text {wick }} \operatorname{Re}_{y, \text { wick }, 2} \frac{h_{\text {wick }, 2}{ }^{2}}{L_{y}{ }^{2}}\right) \ll<1
\end{aligned}
$$

Based on these assumptions, the convection terms in the energy equation for the wicks and the vapor core are considered negligible compared to diffusion in the $z$ direction. Thus,

$$
\begin{gathered}
\rho C_{P, l} u \frac{\partial}{\partial x}<<k \frac{\partial^{2}}{\partial z^{2}}, \rho C_{P, l} v \frac{\partial}{\partial y}<<k \frac{\partial^{2}}{\partial z^{2}}, \\
\rho C_{P, l} w \frac{\partial}{\partial z}<<k \frac{\partial^{2}}{\partial z^{2}}
\end{gathered}
$$

In the two wicks, the permeability is proportional to the square of the particle diameter, which is smaller than the wick thickness. Thus, the following assumptions are made regarding the porous medium:

$$
\frac{K_{\text {wick }}}{\phi_{\text {wick }}}<<h_{\text {wick }, 1}{ }^{2}, \frac{K_{\text {wick }}}{\phi_{\text {wick }}}<<h_{\text {wick }, 2}{ }^{2} \text {. }
$$

Based on these assumptions and the time scales, we may write for the two wicks,

$$
\mu \frac{\partial^{2}}{\partial z^{2}}<<\frac{\mu \phi}{K}, \rho \frac{\partial}{\partial t}<<\frac{\mu \phi}{K} .
$$

Given the above simplifications, the governing momentum and energy equations are simplified. For the vapor core, Eqs. (2) and (3) reduce to: 


$$
\begin{gathered}
\rho \frac{\partial \vec{V}}{\partial t}=-\nabla P+\mu \frac{\partial^{2} \vec{V}}{\partial z^{2}} \\
\left(\rho C_{P}\right)_{e f f}\left(\frac{\partial T}{\partial t}\right)=k_{e f f} \frac{\partial^{2} T}{\partial z^{2}},
\end{gathered}
$$

and for the wick zones to

$$
\begin{gathered}
\nabla(\phi P)=-\frac{\mu \phi}{K} \vec{V} \\
\left(\rho C_{P}\right)_{e f f}\left(\frac{\partial T}{\partial t}\right)=k_{\text {eff }} \frac{\partial^{2} T}{\partial z^{2}} .
\end{gathered}
$$

\subsection{Combined energy equation}

The energy equations for the walls (3), vapor core (23), and wicks (25) are integrated along $z$ in each zone, over their respective thicknesses. Thus, for the evaporator-side wall,

$$
\begin{aligned}
& \left(\rho C_{P}\right)_{e f f}\left(\frac{\partial \bar{T}_{\text {wall }, 1}}{\partial t}\right) \\
& =k_{\text {eff }}\left(\frac{\partial^{2} \bar{T}_{\text {wall }, 1}}{\partial x^{2}}+\frac{\partial^{2} \bar{T}_{\text {wall }, 1}}{\partial y^{2}}\right)+\left.\frac{k_{\text {eff }}}{h_{\text {wall_l }}} \frac{\partial T}{\partial z}\right|_{0} ^{h_{\text {wall }, 1}}
\end{aligned}
$$

for the condenser-side wall,

$$
\begin{aligned}
& \left(\rho C_{P}\right)_{\text {eff }}\left(\frac{\partial \bar{T}_{\text {wall }, 2}}{\partial t}\right)=k_{\text {eff }}\left(\frac{\partial^{2} \bar{T}_{\text {wall }, 2}}{\partial x^{2}}+\frac{\partial^{2} \bar{T}_{\text {wall }, 2}}{\partial y^{2}}\right) \\
& +\left.\frac{k_{\text {eff }}}{h_{\text {wall }, 2}} \frac{\partial T}{\partial z}\right|_{h_{\text {wall }, I}+h_{\text {wick },}+h_{\text {vap }}+h_{\text {wick }, 2}} ^{h_{\text {wall },}+h_{\text {wick },}+h_{\text {vap }}+h_{\text {wick }, 2}+h_{\text {wall }, 2}} ;
\end{aligned}
$$

for the evaporator-side wick,

$$
\left(\rho C_{P}\right)_{\text {eff }}\left(\frac{\partial \bar{T}_{\text {wick }, I}}{\partial t}\right)=\left.\frac{k_{\text {eff }}}{h_{\text {wick }, l}} \frac{\partial T}{\partial z}\right|_{h_{\text {wall }, I}} ^{h_{\text {wall }, I}+h_{\text {wick }, l}}
$$

for the condenser-side wick, 


$$
\left(\rho C_{P}\right)_{\text {eff }}\left(\frac{\partial \bar{T}_{\text {wick }, 2}}{\partial t}\right)=\left.\frac{k_{\text {eff }}}{h_{\text {wick }, 2}} \frac{\partial T}{\partial z}\right|_{h_{\text {wall }, I}+h_{\text {wick }, l}+h_{\text {vap }}} ^{h_{\text {wall },}+h_{\text {wick }, l}+h_{\text {vap }}+h_{\text {wick }, 2}}
$$

and for the vapor core

$$
\left(\rho C_{P}\right)_{\text {eff }}\left(\frac{\partial \bar{T}_{\text {vap }}}{\partial t}\right)=\left.\frac{k_{\text {eff }}}{h_{\text {vap }}} \frac{\partial T}{\partial z}\right|_{h h_{\text {wall }, I}+h_{\text {wick }, I}} ^{h_{\text {wall }, I}+h_{\text {wick }, I}+h_{\text {vap }}}
$$

where $\bar{T}$ is the $z$-averaged temperature in each zone. Information regarding the variation of temperature in the $z$ direction is lost due to the integration. Hence, profiles are assigned to temperature in the $z$ direction. In the walls and the wicks, the temperature difference across the thickness is assumed to be negligible compared to the temperature difference along the $x$ and $y$ directions. The temperature is thus taken to be constant along the $z$ direction. In the vapor core, the temperature is assumed to have a quadratic profile in the $z$ direction. To interface between the zones, continuity is imposed at the zone boundaries. Thus, in the walls and the wicks,

$$
\bar{T}_{\text {wall }, 1}=\bar{T}_{\text {wick }, 1}=\bar{T}_{1} \text { and } \bar{T}_{\text {wall }, 2}=\bar{T}_{\text {wick }, 2}=\bar{T}_{2} .
$$

The temperature in the vapor core can be written as

$$
\begin{aligned}
& T=a\left(z-h_{\text {wall }, 1}-h_{\text {wick }, 1}\right)^{2}+b\left(z-h_{\text {wall }, 1}-h_{\text {wick }, 1}\right)+c, \\
& a=\frac{3\left(\bar{T}_{1}+\bar{T}_{2}-2 \bar{T}_{\text {vap }}\right)}{h_{\text {vap }}{ }^{2}}, b=\frac{6 \bar{T}_{\text {vap }}-4 \bar{T}_{1}-2 \bar{T}_{2}}{h_{\text {vap }}}, c=\bar{T}_{1}
\end{aligned}
$$

Combining the energy equations (26) through (30) for all zones, using the boundary conditions in Eqs. (7), (10) and (12), and the assumed temperature profiles specified by Eqs. (31) and (32), energy transport in the vapor chamber is represented by a linear differential equation with a three-component vector variable, written as 


$$
\begin{aligned}
& \frac{\partial \underline{\Theta}}{\partial t}=\underset{\sim}{A}\left(\frac{\partial^{2} \underline{\Theta}}{\partial x^{2}}+\frac{\partial^{2} \underline{\Theta}}{\partial y^{2}}\right)+\underset{\sim}{B} \underline{\Theta}+\underline{C}, \\
& \underline{\Theta}=\left[\begin{array}{c}
\bar{T}_{1} \\
\bar{T}_{v a p} \\
\bar{T}_{2}
\end{array}\right], \underline{C}=\left[\begin{array}{c}
\frac{q_{i n}^{\prime \prime}-\dot{m}_{1}^{\prime \prime} h_{f g}}{\beta_{1}} \\
0 \\
h T_{\infty}-\dot{m}_{2}^{\prime \prime} h_{f g} \\
\beta_{2}
\end{array}\right] \\
& \beta_{1}=\left(\rho C_{P}\right)_{\text {wall }, 1} h_{\text {wall }, 1}+\left(\rho C_{P}\right)_{\text {eff }, \text { wick }, 1} h_{\text {wick }, 1}, \\
& \beta_{2}=\left(\rho C_{P}\right)_{\text {wall }, 2} h_{\text {wall }, 2}+\left(\rho C_{P}\right)_{\text {eff }, \text { wick }, 2} h_{\text {wick }, 2},
\end{aligned}
$$

The matrices $\underset{\sim}{A}$ (units of $\left[\mathrm{m}^{2} \mathrm{~s}^{-1}\right]$ ) and $\underset{\sim}{B}$ (units of $\left[\mathrm{s}^{-1}\right]$ ) contain thermophysical properties and geometric variables:

$$
\begin{aligned}
\underset{\sim}{A} & =\left[\begin{array}{ccc}
\frac{k_{\text {wall }, 1} h_{\text {wall }, 1}}{\beta_{1}} & 0 & 0 \\
0 & 0 & 0 \\
0 & 0 & \frac{k_{\text {wall }, 2} h_{\text {wall }, 2}}{\beta_{2}}
\end{array}\right], \\
\underset{\sim}{B} & =\left[\begin{array}{ccc}
\frac{-k_{\text {vap }}}{\beta_{1} h_{\text {vap }}} & 0 & 0 \\
0 & \frac{6 k_{\text {vap }}}{h_{\text {vap }}{ }^{2}\left(\rho C_{P}\right)_{\text {vap }}} & 0 \\
0 & 0 & \frac{-k_{\text {vap }}}{\beta_{2} h_{\text {vap }}}
\end{array}\right] \times\left[\begin{array}{ccc}
4 & -6 & 2 \\
1 & -2 & 1 \\
2 & -6 & 4+\frac{h_{\text {vap }} h}{k_{\text {vap }}}
\end{array}\right] .
\end{aligned}
$$

Eq. (33) contains the two unknown mass flux rates due to phase change at the two interfaces, which are solved for in the next two sections.

\subsection{Vapor core hydrodynamics}

The continuity and momentum equations for the vapor core are used to obtain a single equation for the pressure field in this section. The characteristic time scales of thermal diffusion in the $x$ and $y$ directions per the system energy equation (33) are $\sim L_{x}^{2} / \alpha_{\text {wall }}$ and $\sim L_{y}^{2} / \alpha_{\text {wall }}$, 
respectively. The characteristic time scale of momentum diffusion in the $z$ direction per the vapor momentum equation (22) is $\sim h_{v a p}^{2} / \alpha_{\text {vap }}$. For typical vapor chamber geometries and working fluid properties, assuming $h_{v a p}^{2} / \alpha_{\text {vap }}<<L_{x}^{2} / \alpha_{\text {wall }}$, the vapor hydrodynamics can be considered quasi-steady. Thus, the momentum equation (22) in the vapor core reduces to:

$$
\nabla P=\mu \frac{\partial^{2} \vec{V}}{\partial z^{2}} .
$$

Eq. (35) along with the boundary conditions in (7) yields,

$$
\begin{aligned}
& u=\frac{1}{2 \mu} \frac{\partial P}{\partial x}\left(\begin{array}{l}
z^{2}-\left(2 h_{\text {wall }, I}+2 h_{\text {wick }, I}+h_{\text {vap }}\right) z+ \\
\left(h_{\text {wall }, I}+h_{\text {wick }, I}\right)\left(h_{\text {wall }, I}+h_{\text {wick }, I}+h_{\text {vap }}\right)
\end{array}\right), \\
& v=\frac{1}{2 \mu} \frac{\partial P}{\partial y}\left(\begin{array}{l}
z^{2}-\left(2 h_{\text {wall }, I}+2 h_{\text {wick }, I}+h_{\text {vap }}\right) z+ \\
\left(h_{\text {wall }, I}+h_{\text {wick }, I}\right)\left(h_{\text {wall }, I}+h_{\text {wick }, I}+h_{\text {vap }}\right)
\end{array}\right)
\end{aligned}
$$

Substituting velocity relations from Eq. (36) into the mass conservation in Eq. (1) and integrating along $\mathrm{z}$ over the vapor core thickness, using the boundary conditions in (7), yields

$$
\frac{\partial^{2} P}{\partial x^{2}}+\frac{\partial^{2} P}{\partial y^{2}}=-\frac{12 \mu}{\rho h_{v a p}^{3}}\left(\dot{m}_{2}^{\prime \prime}+\dot{m}_{1}^{\prime \prime}\right)
$$

\subsection{Coupling energy equation with vapor hydrodynamics}

In this section, the unknown mass flux rates in Eq. (33) are related to the pressure field in the vapor core and the temperature field. The Clausius-Clapeyron equation (5) is simplified by assuming a linear relation between the vapor pressure and saturation temperature. Thus, the right hand side of the equation is substituted by an average in the field

$$
\frac{d P}{d T_{\text {sat }}}=\lambda=\frac{h_{f g} P_{O}}{R\left(T_{\text {sat }}^{2}\right)_{\text {mean }}},
$$


where $P_{O}$ is the saturation pressure corresponding to the volume-averaged vapor core temperature, and $\left(T_{\text {sat }}^{2}\right)_{\text {mean }}$ is the volume average value of $T_{\text {sat }}^{2}$ in the vapor core. The computation of the mass flux rate due to phase change (Eq. (4)) is simplified to create a linear relation with the difference in the interface temperature and the vapor core saturation temperature. Thus,

$$
\begin{aligned}
& \dot{m}^{\prime \prime}=\varphi\left(T_{\text {int }}-T_{\text {sat }}\right), \\
& \varphi=\frac{2 \sigma}{2-\sigma} \frac{h_{\text {fg }} \rho_{\text {vap }}}{\left(T_{\text {vap }}^{1.5}\right)_{\text {mean }}}\left(\frac{1}{2 \pi R}\right)^{0.5}
\end{aligned}
$$

where $\left(T_{\text {vap }}{ }^{1.5}\right)_{\text {mean }}$ is the volume-averaged value of $T_{\text {vap }}{ }^{1.5}$. The $T_{\text {sat }}$ value at the interface on the evaporator side is equal to $\bar{T}_{1}$ and at the interface on the condenser side is equal to $\bar{T}_{2}$. The pressure variable in Eq. (37) is substituted with the saturation temperature using Eq. (38). The mass flux rate terms in Eq. (37) are replaced using (39). Thus, an equation is obtained for the saturation temperature as

$$
\lambda\left(\frac{\partial^{2} T_{\text {sat }}}{\partial x^{2}}+\frac{\partial^{2} T_{\text {sat }}}{\partial y^{2}}\right)=-\frac{12 \mu_{\text {vap }}}{\rho_{\text {vap }} h_{\text {vap }}{ }^{3}} \varphi\left(\bar{T}_{1}+\bar{T}_{2}-2 T_{\text {sat }}\right) .
$$

The boundary conditions for saturation temperature are obtained from Eq. (6), using the relations from Eq. (36) and Eq. (38).

$$
\begin{aligned}
& \text { at } x=0 \text { and } x=L_{x}, \\
& u=0 \Rightarrow \frac{\partial P}{\partial x}=0 \Rightarrow \frac{\partial T_{\text {sat }}}{\partial x}=0 \\
& \text { at } y=0 \text { and } y=L_{y}, \\
& v=0 \Rightarrow \frac{\partial P}{\partial y}=0 \Rightarrow \frac{\partial T_{\text {sat }}}{\partial y}=0
\end{aligned}
$$

\subsection{Solution to the combined energy equation}


The combined energy equation (Eq. (33)) and the saturation temperature equation (Eq. (40)) are solved using Fourier series substitution. For the combined energy equation, the substitution

$$
\begin{aligned}
& \underline{\Theta}=\left[\begin{array}{c}
\bar{T}_{1} \\
\bar{T}_{v a p} \\
\bar{T}_{2}
\end{array}\right]=\sum_{l=0}^{\infty} \sum_{k=0}^{\infty}\left(\underline{a}_{l k} \cos \left(\frac{l \pi x}{L_{x}}\right) \cos \left(\frac{k \pi y}{L_{y}}\right)\right), \\
& \text { where } \underline{\underline{a}}_{l k}=\left[\begin{array}{c}
a_{1} \\
a_{v a p} \\
a_{2}
\end{array}\right]_{l k}
\end{aligned}
$$

is used. This satisfies the boundary conditions in Eqs. (6), (8), and (11) at $x=0, x=L_{x}, y=0$ and $y=L_{y}$. For the saturation temperature equation, the substitution

$$
T_{s a t}=\sum_{l=0}^{\infty} \sum_{k=0}^{\infty}\left(c_{l k} \cos \left(\frac{l \pi x}{L_{x}}\right) \cos \left(\frac{k \pi y}{L_{y}}\right)\right)
$$

satisfies the boundary conditions in Eq. (41). Substituting Eqs. (42) and (43) into Eq. (40) yields

$$
c_{l k}=\frac{\left[\begin{array}{lll}
1 & 0 & 1
\end{array}\right] \underline{a}_{l k}}{\left(\frac{\lambda \rho_{\text {vap }} h_{v a p}{ }^{3}}{12 \mu_{\text {vap }} \varphi} \pi^{2}\left(\frac{l^{2}}{L_{x}{ }^{2}}+\frac{k^{2}}{L_{y}{ }^{2}}\right)+2\right)} .
$$

The mass flux rate defined in Eq. (39) is substituted into Eq. (33); $\underline{\Theta}$ in Eq. (33) is substituted using Eq. (42), and $T_{\text {sat }}$ (introduced from Eq. (39)) is substituted using Eq. (43). Eq. (44) is then used to eliminate the $c_{l k}$ variable:

$$
\sum_{l=0}^{\infty} \sum_{k=0}^{\infty}\left(\underline{b}_{l k} \cos \left(\frac{l \pi x}{L_{x}}\right) \cos \left(\frac{k \pi y}{L_{y}}\right)\right)=\left[\begin{array}{c}
\frac{q_{i n}^{\prime \prime}}{\beta_{1}} \\
0 \\
\frac{h T_{\infty}}{\beta_{2}}
\end{array}\right],
$$


where

$$
\underline{b}_{l k}=\frac{\partial \underline{a}_{l k}}{\partial t}+\underline{G}_{\underline{a}_{k}}
$$

The matrix $\underset{\sim}{G}$ contains thermophysical and geometric parameters.

$$
\begin{aligned}
& \underset{\sim}{G}=\underset{\sim}{A}\left(\frac{l^{2}}{L_{x}^{2}}+\frac{k^{2}}{L_{y}^{2}}\right)-\underset{\sim}{B} \\
& -\left[\begin{array}{ccc}
\frac{-\varphi h_{f g}}{\beta_{1}} & 0 & 0 \\
0 & 0 & 0 \\
0 & 0 & \frac{-\varphi h_{f g}}{\beta_{2}}
\end{array}\right] \\
& -\left[\begin{array}{c}
\frac{\varphi h_{f g}}{\beta_{1}} \\
0 \\
\frac{\varphi h_{f g}}{\beta_{2}}
\end{array}\right]\left[\begin{array}{cc}
\frac{\lambda \rho h_{v a p}^{3}}{12 \mu \varphi} \pi^{2}\left(\frac{l^{2}}{L_{x}^{2}}+\frac{k^{2}}{L_{y}^{2}}\right)+2
\end{array}\right)
\end{aligned}
$$

The left hand side of Eq. (45) is a 2D Fourier series. The coefficients of a 2D Fourier series are computed using

$$
\begin{aligned}
& \underline{b}_{l k}=\frac{\delta_{l k}}{L_{x} L_{y}} \int_{0}^{L_{y}} \int_{0}^{L_{x}}\left[\begin{array}{c}
\frac{q_{i n}^{\prime \prime}}{\beta_{1}} \\
0 \\
\frac{h T_{\infty}}{\beta_{2}}
\end{array}\right] \cos \left(\frac{l \pi x}{L_{x}}\right) \cos \left(\frac{k \pi y}{L_{y}}\right) d x d y, \\
& \delta_{l k}=4 \text { for } l>0 \text { and } k>0 \\
& \delta_{l k}=2 \text { for } l=0 \text { and } k>0 \text { or } l>0 \text { and } k=0 \\
& \delta_{l k}=1 \text { for } l=0 \text { and } k=0
\end{aligned}
$$

Eq. (46) is solved by discretizing it in time using a backward difference approximation. Thus, 


$$
\underline{b}_{l k}^{n+1}=\frac{\underline{a}_{l k}^{n+1}-\underline{a}_{l k}^{n}}{\Delta t}+\underline{\sigma}_{a_{k}^{n+1}}
$$

by rearranging terms,

$$
\underline{a}_{l k}^{n+1}=\left(I_{3}+\Delta t \underline{\sim}\right)^{-1}\left(\Delta t \underline{b}_{l k}^{n+1}+\underline{a}_{l k}^{n}\right)
$$

where $n$ is the time step number. The initial values of $\underline{a}_{l k}$ are computed based on the temperature at time zero.

$$
\underline{a}_{l k}^{0}=\frac{\delta_{l k}}{L_{x} L_{y}} \int_{0}^{L_{y}} \int_{0}^{L_{x}}\left[\begin{array}{c}
\bar{T}_{1}^{0} \\
\bar{T}_{v a p}^{0} \\
\bar{T}_{2}^{0}
\end{array}\right] \cos \left(\frac{l \pi x}{L_{x}}\right) \cos \left(\frac{k \pi y}{L_{y}}\right) d x d y
$$

where $\bar{T}_{1}^{0}, \bar{T}_{\text {vap }}^{0}$, and $\bar{T}_{2}^{0}$ are the initial temperatures.

At each time step, using the known boundary heat flux at the evaporator, Eq. (48) is solved to obtain $\underline{b}_{l k}$. This is used to solve the time stepping Eq. (49) to obtain $\underline{a}_{l k}$. The computed $\underline{a}_{k}$ value is used to compute $c_{l k}$ using Eq. (44). Once these coefficients are obtained, the temperature field in the vapor chamber and the saturation temperature in the vapor core can be computed. The pressure and velocity fields can then be computed.

\subsection{Wick hydrodynamics}

The continuity and momentum equations in the wick zones are combined to compute the wick pressure field. The momentum equation in the wick (Eq. (24)) combined with the continuity equation (Eq. (1)) yields equations for the pressure in the evaporator-side and condenser-side wicks, respectively, as

$$
\begin{aligned}
& \left(\frac{\partial^{2} P_{\text {wick }, 1}}{\partial x^{2}}+\frac{\partial^{2} P_{\text {wick }, 1}}{\partial y^{2}}\right)=\frac{\dot{m}_{1}^{\prime \prime} \mu}{\rho K_{\text {wick }, 1} h_{\text {wick }, 1}} . \\
& \left(\frac{\partial^{2} P_{\text {wick, }, 2}}{\partial x^{2}}+\frac{\partial^{2} P_{\text {wick }, 2}}{\partial y^{2}}\right)=\frac{\dot{m}_{2}^{\prime \prime} \mu}{\rho K_{\text {wick }, 2} h_{\text {wick }, 2}}
\end{aligned}
$$


Setting $P_{\text {sum }}=P_{\text {wick }, l}+P_{\text {wick }, 2}$ and $P_{\text {diff }}=P_{\text {wick }, I}-P_{\text {wick }, 2}$, Eq. (51) yields

$$
\begin{aligned}
& \left(\frac{\partial^{2} P_{\text {sum }}}{\partial x^{2}}+\frac{\partial^{2} P_{\text {sum }}}{\partial y^{2}}\right)=\frac{\dot{m}_{1}^{\prime \prime} \mu}{\rho K_{\text {wick }, l} h_{\text {wick }, l}}+\frac{\dot{m}_{2}^{\prime \prime} \mu}{\rho K_{\text {wick }, 2} h_{\text {wick }, 2}} . \\
& \left(\frac{\partial^{2} P_{\text {diff }}}{\partial x^{2}}+\frac{\partial^{2} P_{\text {diff }}}{\partial y^{2}}\right)=\frac{\dot{m}_{1}^{\prime \prime} \mu}{\rho K_{\text {wick },} h_{\text {wick }, l}}-\frac{\dot{m}_{2}^{\prime \prime} \mu}{\rho K_{\text {wick }, 2} h_{\text {wick }, 2}}
\end{aligned}
$$

Based on the boundary conditions given by Eq. (8) and the wick momentum Eq. (24), the boundary conditions for $P_{\text {sum }}$ and $P_{\text {diff }}$ are

$$
\begin{aligned}
& \text { at } x=0 \text { and } x=L_{x}, u_{\text {sum }}=0=\frac{\partial P_{\text {sum }}}{\partial x} ; P_{\text {diff }}=0 \\
& \text { at } y=0 \text { and } y=L_{y}, v_{\text {sum }}=0=\frac{\partial P_{\text {sum }}}{\partial y} ; P_{\text {diff }}=0
\end{aligned}
$$

where $u_{\text {sum }}=u_{\text {wick }, 1}+u_{\text {wick }, 2}$ and $u_{\text {diff }}=u_{\text {wick }, 1}-u_{\text {wick }, 2}$. To solve the Laplacians in Eq. (52), 2D

Fourier series substitutions are used.

$$
\begin{gathered}
P_{\text {sum }}=\sum_{l=0}^{\infty} \sum_{k=0}^{\infty}\left(d_{\text {sum }, l k} \cos \left(l \pi \frac{x}{L_{x}}\right) \cos \left(k \pi \frac{y}{L_{y}}\right)\right) \\
P_{\text {diff }}=\sum_{l=0}^{\infty} \sum_{k=0}^{\infty}\left(d_{\text {diff, }, k} \sin \left(l \pi \frac{x}{L_{x}}\right) \sin \left(k \pi \frac{y}{L_{y}}\right)\right)
\end{gathered}
$$

satisfy the boundary conditions in Eq. (53). Substituting into Eq. (52) yields 


$$
\begin{aligned}
& -\sum_{l=0}^{\infty} \sum_{k=0}^{\infty}\left(\begin{array}{l}
d_{\text {sum }, k} \pi^{2}\left(\left(\frac{l}{L_{x}}\right)^{2}+\left(\frac{k}{L_{y}}\right)^{2}\right) \\
\cos \left(l \pi \frac{x}{L_{x}}\right) \cos \left(k \pi \frac{y}{L_{y}}\right)
\end{array}\right) \\
& =\frac{\dot{m}_{1}^{\prime \prime} \mu}{\rho K_{\text {wick }, l} h_{\text {wick }, l}}+\frac{\dot{m}_{2}^{\prime \prime} \mu}{\rho K_{\text {wick }, 2} h_{\text {wick }, 2}} \\
& -\sum_{l=0}^{\infty} \sum_{k=0}^{\infty}\left(\begin{array}{l}
d_{d i f f, l k} \pi^{2}\left(\left(\frac{l}{L_{x}}\right)^{2}+\left(\frac{k}{L_{y}}\right)^{2}\right) \\
\cos \left(l \pi \frac{x}{L_{x}}\right) \cos \left(k \pi \frac{y}{L_{y}}\right)
\end{array}\right) \\
& =\frac{\dot{m}_{1}^{\prime \prime} \mu}{\rho K_{\text {wick },} h_{\text {wick }, l}}-\frac{\dot{m}_{2}^{\prime \prime} \mu}{\rho K_{\text {wick }, 2} h_{\text {wick }, 2}}
\end{aligned}
$$

Using the formula for the coefficients of a 2D Fourier series yields

$$
\begin{aligned}
& d_{\text {sum }, l k}=\frac{\left.\delta_{l k} \int_{0}^{L_{y} \int_{x}} \int_{0}^{\left(\frac{\dot{m}_{1}^{\prime \prime} \mu}{\rho K_{\text {wick }, l} h_{\text {wick }, l}}+\frac{\dot{m}_{2}^{\prime \prime} \mu}{\rho K_{\text {wick }, 2} h_{\text {wick }, 2}}\right)}\right) d x d y}{-\pi^{2}\left(\left(\frac{l}{L_{x}}\right)^{2}+\left(\frac{k}{L_{x}}\right)^{2}\right) L_{x} L_{y}} \\
& d_{\text {diff, }, k}=\frac{4 \int_{0}^{L_{L_{y}} \int_{0}}\left(\begin{array}{l}
\left(\frac{\dot{m}_{1}^{\prime \prime} \mu}{\rho K_{\text {wick }, l} h_{\text {wick }, l}}-\frac{\dot{m}_{2}^{\prime \prime} \mu}{\rho K_{\text {wick }, 2} h_{\text {wick }, 2}}\right) \\
\left(\cos \left(\frac{l \pi x}{L_{x}}\right) \cos \left(\frac{k \pi y}{L_{y}}\right)\right)
\end{array}\right) d x d y}{-\pi^{2}\left(\left(\frac{l}{L_{x}}\right)^{2}+\left(\frac{k}{L_{y}}\right)^{2}\right) L_{x} L_{y}}
\end{aligned}
$$


The velocity fields in the wick can then be computed using the governing momentum equation (24).

\subsection{Model implementation}

A time-stepping based model is developed for the vapor chamber transport that computes the 3D fields of temperature in the vapor chamber, as well as the pressure and velocity fields in the wick and the vapor core. The temperature-dependent thermophysical properties of the fluid are computed at each time step based on the volume-averaged temperature for the corresponding zone. The infinite-series sums in the model are truncated to finite sums whose number is chosen such that adding another term does not change the magnitude significantly.

$$
\text { sum }=\sum_{i=0}^{\infty} v a r_{i} \approx \sum_{i=0}^{N} v a r_{i}
$$

where var is the summand of the series.

It is important to note that using a time-discretized solution method allows for the use of temperature-dependent properties for the vapor phase. The vapor phase properties can be expected to change considerably over the range of typical operating temperatures (from the initial ambient to full-power operation), and thus temperature-dependent properties are necessary for achieving reasonable accuracy of the model. Combining analytical and time-discretized solution methods in this manner allows for a low-computational cost without sacrificing accuracy.

\section{Estimation of model accuracy}

The accuracy of the time-stepping analytical model depends on the validity of the assumptions underlying each of the simplifications to the governing equations. The Supplementary Material describes an estimate of the errors in the temperature and pressure fields computed by the model as a result of the simplifying assumptions for a range of vapor chamber 
thicknesses and input power. Based on this analysis, the following three assumptions were found to cause the largest errors in the temperature and pressure fields across the simulated cases: (1) assuming a negligible temperature difference across the thickness of the wall and the wick on the evaporator side (Eq. (31)); (2) linearizing the Clausius-Clapeyron equation (Eq. (38)); and (3) neglecting convection in the momentum equation in the vapor core (Eq. (17)).

As detailed in the Supplementary Material, at the most extreme working thickness and operating power, the relative error in the maximum temperature drop is only $30 \%$; for most of the simulated cases, the error is under $10 \%$. Similarly, the total pressure drop in the vapor chamber is generally predicted with good accuracy. Thus the model has excellent accuracy in computing the maximum temperature drop and total pressure drop in a vapor chamber over a wide range of thicknesses and powers.

\section{Results}

\subsection{Model validation}

The predictions of the time-stepping analytical vapor chamber model developed in this work are validated against a numerical model for the same geometry, materials, and boundary conditions. This benchmark numerical model is the finite-volume-based vapor chamber model described in Ref. [6] (without the microscale model corrections to the evaporation rate and interfacial area). Two validation cases were simulated comparing the time-stepping analytical model against the benchmark numerical model for the same geometry and boundary conditions as described in Figure 3; Figure 3a shows Case \#1 and Figure 3b shows Case \#2. For both cases, the vapor chamber has copper walls with a uniform layer of sintered copper wick on the inner surface of the walls. The length and width of the vapor chamber are $L_{x}=90 \mathrm{~mm}$ and $L_{y}=55 \mathrm{~mm}$, respectively. The thickness of the walls are $h_{\text {wall }, 1}=h_{\text {wall, }, 2}=0.2 \mathrm{~mm}$. The thickness of the wicks 
in Case \#1 are $h_{\text {wick, },}=h_{\text {wick }, 2}=37 \mu \mathrm{m}$, and in Case \#2 are $h_{\text {wick }, 1}=h_{\text {wick }, 2}=120 \mu \mathrm{m}$. The thickness of the vapor core in Case \#1 is $h_{v a p}=26 \mu \mathrm{m}$, and in Case $\# 2$ is $h_{v a p}=360 \mu \mathrm{m}$. Water is used as the working fluid. The properties of the working fluid, copper, and porous wick materials are shown in Table 2 . The vapor chamber is initially at a uniform temperature of $300 \mathrm{~K}$. Starting at $t$ $=0 \mathrm{~s}$, the vapor chamber receives a heat input power $10 \mathrm{~W}$ for Case \#1 and $160 \mathrm{~W}$ for Case \#2, applied over a square area of $1 \mathrm{~cm}^{2}$ at the center of the evaporator side; the rest of the evaporator-side face is insulated. The opposing condenser side experiences a convective boundary condition with a heat transfer coefficient of $75 \mathrm{~W} / \mathrm{m}^{2} \mathrm{~K}$ for Case \#1 and of 1200 $\mathrm{W} / \mathrm{m}^{2} \mathrm{~K}$ for Case $\# 2$, and an ambient temperature of $300 \mathrm{~K}$. The sides of the vapor chamber are insulated.

The time-stepping analytical model is solved using the commercial software MATLAB [16]; the temperature-dependent properties of the water vapor are obtained using the commercial software REFPROP [17]. Each infinite-series summation is truncated to 40 terms. The finitevolume numerical vapor chamber model is implemented in the commercial software FLUENT [18]; the vapor chamber geometry is discretized into a rectangular grid with 540,000 cells. The complete transient behavior of Case \#1 was simulated using variable time-steps in the range of $0.1 \mathrm{~s}$ to $2 \mathrm{~s}$. Case \#2 was simulated to obtain a comparison at steady-state, using the steady-stateseeking solution algorithm described in Ref. [3]. The simulation with the time-stepping analytical model uses a time step of $0.1 \mathrm{~s}$ for both the simulations.

The temperature fields predicted by the two different modeling approaches for Case \#1 are shown in Figure 4. Figure 4a shows the spatial temperature variation, while Figure 4b shows the temporal temperature variation. Figure 4 a shows the spatial temperature variation along two lines on the evaporator-side ( $\mathrm{z}=0 \mathrm{~mm}, y=27.5 \mathrm{~mm})$ and condenser-side $(z=0.5 \mathrm{~mm}, y=27.5 \mathrm{~mm})$ 
vapor chamber faces at $t=44.5 \mathrm{~s}$. The temperature profile has a maximum temperature at $x=45$ $\mathrm{mm}$ for both the curves and decreases in both directions away from the center. A temperature difference between the evaporator and condenser sides is also apparent from the plots. The plots reveal a good match between the two simulations for the prediction of spatial temperature variation; the relative error in the total temperature drop in the vapor chamber is 0.075 . In Section 3, it was estimated that the temperature field would have no error due to the linearization of the Clausius-Clapeyron equation, but would primarily manifest as an error in the pressure field. We note here that the linearization of the Clausius-Clapeyron equation does lead to an error in the temperature field, albeit one that is small compared to the effect on the pressure field. Figure $4 \mathrm{~b}$ shows the temporal variation of maximum temperature in the vapor chamber, which increases with time due to the heat input applied to vapor chamber; the predictions with the two approaches again match very well.

Figure 5 shows the pressure fields in the wicks (Figure 5a) and the vapor core (Figure 5b) at $t$ $=44.5 \mathrm{~s}$ on the cross-sectional plane $(y=27.5 \mathrm{~mm})$ shown in Figure 3, for Case \#1. The pressure values in both the plots are offset from the absolute pressure such that the relative pressure value is zero at $x=0 \mathrm{~mm}$ and $x=90 \mathrm{~mm}$. The pressure in the wick is highest at the center of the condenser-side wick and reduces outward in the direction of liquid flow. Once the liquid returns to the evaporator side at the peripheries the pressure reduces as liquid flows toward the center of the heated region. The pressure in the vapor core is highest at the center where vapor is generated in the vicinity of the heat input and reduces in the outward direction of vapor flow. The plot reveals a good match between the two simulations for the relative pressure in the wick and the vapor core, except near the heat input. Section 3 estimated that the error for this case would be mainly due to use of the linearized Clausius-Clapeyron relation and should appear in the vapor 
core pressure. The vapor core pressure plots show this predicted error; the error in the pressure gradients is high near the heat input zone, where the pressure is noticeably higher than the average pressure in the vapor core. The wick pressure plot also shows a slight mismatch near the heat input, on the evaporator side. This mismatch is due to a change in the local evaporated mass flux corresponding to the differences in the vapor core pressure field. The relative error in the total pressure drop in the wick is 0.096 , which matches the value predicted by the error estimation analysis (0.095).

The steady-state temperature fields predicted by the two modeling approaches for Case \#2 are shown in Figure 6. The temperature profiles are shown along two lines on the evaporator-side $(\mathrm{z}=0 \mathrm{~mm}, y=27.5 \mathrm{~mm})$ and condenser-side $(z=1 \mathrm{~mm}, y=27.5 \mathrm{~mm})$ vapor chamber faces. The temperature profiles have a maximum temperature at $x=45 \mathrm{~mm}$ and decrease in both directions away from the center. Unlike Case \#1, the temperature variation on the condenser side is negligible compared to that on the evaporator side. The reason is that the comparatively thick vapor core leads to a very small vapor core resistance as compared to the resistance due to phase change across the vapor core. The relative error in the total temperature drop in the vapor chamber is 0.08 , which is lower than the value estimated in the previous section $(0.21)$, albeit in the opposite direction. This is because the thermal convection in the vapor core (which is neglected in the simplified governing equation) reduces the resistance due to phase change; this indirect error cannot be accounted for using the methods employed in Section 3.

Figure 7 shows the pressure fields in the wicks (Figure 7a) and the vapor core (Figure 7b) at steady state on the cross-sectional plane $(y=27.5 \mathrm{~mm})$ shown in Figure 3, for Case \#2. The pressure values in both the plots are offset from the absolute pressure such that the relative pressure value at $x=0 \mathrm{~mm}$ and $x=90 \mathrm{~mm}$ is zero. The pressure profiles in the wick and the 
vapor core have a similar trend as observed in Case \#1. The vapor core pressure predicted by the time-stepping analytical model deviates from the simulation with the finite-volume based numerical model, which is attributed to neglecting the convection term in the momentum equation in the vapor core, as discussed in Section 3. The wick pressure plot also shows a mismatch near the heat input on the evaporator side. This mismatch is due to the change in the local evaporated mass flux associated with the differences in the vapor core pressure field. The relative error in the total pressure drop in the wick is 0.086 , which matches the value predicted by the error estimation analysis (0.095).

The errors in the temperature and pressure profiles of the time-stepping analytical model are remarkably low, both in time and space, considering the significantly reduced computational cost. For Case\#1, the computational time for the finite-volume numerical simulation, on a supercomputer node (Xeon-E5, Intel) using 15 parallel processes, is $319 \mathrm{hr}$. The computational time is reduced to $0.4 \mathrm{hr}$ for the time-stepping analytical model running on a desktop computer, which is a reduction of 3 orders of magnitude.

\subsection{Time-stepping analytical model simulation with multiple time-varying heat inputs}

The time-stepping analytical model is demonstrated for a case where the vapor chamber is subjected to multiple time-varying heat inputs. For this case, the vapor chamber uses the same materials and properties as the previous case (Table 2), with a modified geometry. The length and width of the vapor chamber are $L_{x}=80 \mathrm{~mm}$ and $L_{y}=60 \mathrm{~mm}$, respectively. The wall thicknesses are $h_{\text {wall, }, 1}=h_{\text {wall }, 2}=0.2 \mathrm{~mm}$, with wick thicknesses of $h_{\text {wick }, 1}=h_{\text {wick, } 2}=30 \mu \mathrm{m}$ and a vapor core thickness of $h_{v a p}=40 \mu \mathrm{m}$. The vapor chamber is initially at a uniform temperature of $300 \mathrm{~K}$. Starting at $t=0 \mathrm{~s}$, it is subjected to two heat inputs (Heaters A and B) of $0.5 \mathrm{~W}$ each over separate square areas of $1 \mathrm{~cm}^{2}$ at the locations identified in Figure 8. At $t=50 \mathrm{~s}$, Heater B is 
switched off $(0 \mathrm{~W})$ and Heater A remains on at $0.5 \mathrm{~W}$. The rest of the evaporator-side face is insulated. A convective boundary condition, with heat transfer coefficient $15 \mathrm{~W} / \mathrm{m}^{2} \mathrm{~K}$ and ambient temperature of $300 \mathrm{~K}$, is imposed on the opposing condenser-side face. The sides of the vapor chamber are insulated. In the time-stepping analytical solution, the simulation truncates each infinite-series summation to 40 terms, and is run for 100 time steps of $1 \mathrm{~s}$ each.

Results for the temperature field from the time-stepping analytical solution are shown in Figure 9. Figure 9a shows the temporal variation of the maximum temperature at the center of both heat inputs. The maximum temperatures of Heater A and Heater B both increase at a similar rate upon the initial imposition of $0.5 \mathrm{~W}$ heat inputs to each. Heater B is switched off at $t=50 \mathrm{~s}$, and the temperature at this location decreases suddenly. After $t=53 \mathrm{~s}$, the temperatures at both Heaters A and B increase due to the heat input at Heater A, albeit at a lower rate than before $t=$ $50 \mathrm{~s}$, due to the lower total heat input. A video with the 3D and transient contours of temperature is included in the Supplementary Materials (snapshot in Figure 9b) Figure 9c and Figure 9d show the temperature contours on the vapor chamber condenser-side outer surface at $t=33 \mathrm{~s}$ and $66 \mathrm{~s}$, respectively. The contours at $t=33 \mathrm{~s}$ reveal the non-uniform temperature field that results from the two localized heat inputs. The temperature at Heater B is higher than at Heater A, despite the heaters having the same input power and size, because Heater B is closer to the edges of the vapor chamber. The contours at $t=66 \mathrm{~s}$ only shows only one hotspot, which corresponds to Heater A, since Heater B is switched off at $t=50 \mathrm{~s}$. The simulation is able to capture the transient thermal response of a vapor chamber to multiple time-varying heat inputs.

\section{Conclusions}

A transient model for vapor chamber operation was developed that allows for multiple, arbitrarily shaped, time-varying heat inputs on the evaporator-side face; the model predicts 3D 
fields of temperature, pressure, and velocity in the vapor chamber. The governing mass, momentum, and energy equations in the wall, wick, and vapor core domains were simplified based on a scaling analysis and assuming temperature profiles across the thickness of each zone. The simplified linear differential equations were solved using a combination of analytical and time-discretized methods. The errors introduced into the temperature and pressure fields computed by the time-stepping analytical model due to the simplifying assumptions employed in the model development were estimated. The model has low errors for cases from low- to highpower applications (less than $10 \%$ for a majority of the simulated cases). The model is validated against a finite-volume-based numerical model for two cases, one for a low-power application and another for a high-power application. Based on this validation case, the newly developed time-stepping analytical model was demonstrated to have 3-4 orders of magnitude lower computational cost compared to the numerical model while maintaining good physical accuracy. This model was then used to simulate the behavior of a vapor chamber subjected to multiple, time-varying heat input boundary conditions to demonstrate the capability of the time-stepping analytical model to resolve the transient 3D thermal response to complex boundary conditions expected in real-world applications.

\section{Acknowledgement}

Financial support for this work provided by members of the Cooling Technologies Research Center, a National Science Foundation Industry/University Cooperative Research Center at Purdue University is gratefully acknowledged.

\section{Appendix A. Supplementary Material}


Supplementary material associated with this article can be found in the online version.

\section{References}

[1] T. Shioga and Y. Mizuno, "Micro loop heat pipe for mobile electronics applications," in 31st Thermal Measurement, Modeling Management Symposium (SEMI-THERM), San Jose, CA, USA, pp. 50-55, 2015.

[2] J. A. Weibel and S. V. Garimella, "Recent advances in vapor chamber transport characterization for high-heat-flux applications," Advances in Heat Transfer, vol. 45, pp. 209-301, 2013.

[3] G. Patankar, J. A. Weibel, and S. V. Garimella, "Patterning the condenser-side wick in ultra-thin vapor chamber heat spreaders to improve skin temperature uniformity of mobile devices," International Journal of Heat and Mass Transfer., vol. 101, pp. 927-936, 2016.

[4] U. Vadakkan, S. V. Garimella, and J. Y. Murthy, "Transport in flat heat pipes at high heat fluxes from multiple discrete sources," Journal of Heat Transfer, vol. 126, no. 3, pp. 347354, 2004.

[5] R. Ranjan, J. Y. Murthy, S. V. Garimella, and U. Vadakkan, "A numerical model for transport in flat heat pipes considering wick microstructure effects," International Journal of Heat and Mass Transfer, vol. 54, no. 1-3, pp. 153-168, 2010.

[6] R. Ranjan, J. Y. Murthy, S. V. Garimella, D. H. Altman, and M. T. North, "Modeling and design optimization of ultrathin vapor chambers for high heat flux applications," IEEE Transactions on Components, Packaging and Manufacturing Technology, vol. 2, no. 9, pp. 1465-1479, 2012.

[7] M. Famouri, M. Abdollahzadeh, G. H. Huang, A. Abdulshaheed, G. Carbajal, and C. Li, "Transient analysis of a cylindrical heat pipe considering different wicks structures," in Proceedings of the ASME Heat Transfer Summer Conference, Washington, DC, USA, 2016.

[8] S. Harmand, R. Sonan, M. Fakès, and H. Hassan, "Transient cooling of electronic components by flat heat pipes," Applied Thermal Engineering, vol. 31, no. 11-12, pp. 1877-1885. 2011.

[9] R. S. Prasher, "A simplified conduction based modeling scheme for design sensitivity study of thermal solution utilizing heat pipe and vapor chamber technology," Journal of Electronics Packaging, vol. 125, no. 3, pp. 378-385, 2003.

[10] Y. Yadavalli, J. A. Weibel, and S. V. Garimella, "Performance-governing transport mechanisms for heat pipes at ultrathin form factors," IEEE Transactions on Components, Packaging and Manufacturing Technology, vol. 5, no. 11, pp. 1618-1627, 2015. 
[11] M. Aghvami and A. Faghri, "Analysis of flat heat pipes with various heating and cooling configurations," Applied Thermal Engineering, vol. 31, no. 14-15, pp. 2645-2655, 2011.

[12] F. Lefèvre and M. Lallemand, "Coupled thermal and hydrodynamic models of flat micro heat pipes for the cooling of multiple electronic components," International Journal of Heat and Mass Transfer, vol. 49, no. 7-8, pp. 1375-1383, 2006.

[13] N. Zhu and K. Vafai, "Analytical modeling of the startup characteristics of asymmetrical flat-plate and diskshaped heat pipes," International Journal of Heat and Mass Transfer, vol. 41, no. 17, pp. 2619-2637, 1998.

[14] V. P. Carey, Liquid-vapor phase-change phenomena, Bristol, PA, Taylor and Francis, 1992.

[15] R. Marek and J. Straub, "Analysis of the evaporation coefficient and the condensation coefficient of water," International Journal of Heat and Mass Transfer, vol. 44, no. 1, pp. $39-53,2001$.

[16] MATLAB 2012a. Natick, Massachusetts, United States: The MathWorks, Inc.

[17] E. W. Lemmon, M. L. Huber, and M. O. McLinden, NIST Standard Reference Database 23: Reference Fluid Thermodynamic and Transport Properties-REFPROP, Version 9.1, National Institute of Standards and Technology, Standard Reference Data Program. Gaithersburg, 2013.

[18] Fluent, “ANSYS FLUENT 14. 0 User's Guide.” ANSYS Fluent, Canonsburg, PA, 2011. 


\section{List of Figures}

Figure 1. Cross-sectional view of vapor chamber operation that illustrates the key components and transport mechanisms.

Figure 2. Vapor chamber transport model geometry and boundary conditions (cross-section and bottom views).

Figure 3. Schematic diagram of the simulated geometry and boundary conditions used to validate the time-stepping analytical vapor chamber model, showing a bottom view at the bottom and cross-section at the top for (a) Case \#1 (thickness scaled 50×), and (b) Case \#2 (thickness scaled $25 \times)$

Figure 4. Comparison of temperature results from vapor chamber simulations using the timestepping analytical model and the finite-volume numerical model for Case \#1. (a) The temperature profile is shown along the evaporator-side outer surface (solid lines; $z=0 \mathrm{~mm}, y=$ $27.5 \mathrm{~mm}$ ) and the condenser-side outer surface (dashed lines; $z=0.5 \mathrm{~mm}, y=27.5 \mathrm{~mm}$ ), at $t=$ $44.5 \mathrm{~s}$. (b) The variation of the maximum temperature in the vapor chamber (at $z=0 \mathrm{~mm}, x=45$ $\mathrm{mm}, y=27.5 \mathrm{~mm}$ ) with time predicted by the two models is compared.

Figure 5. Comparison of pressure results from the vapor chamber simulations using the timestepping analytical model and the finite-volume numerical model for Case \#1. The relative pressure variation in the (a) wick and (b) vapor core are shown for the cross-sectional plane $y=$ $27.5 \mathrm{~mm}$ at $t=44.5 \mathrm{~s}$.

Figure 6. Comparison of the temperature profile along the evaporator-side outer surface (solid lines; $z=0 \mathrm{~mm}, y=27.5 \mathrm{~mm}$ ) and the condenser-side outer surface (dashed lines; $z=1 \mathrm{~mm}, y=$ $27.5 \mathrm{~mm}$ ), at steady-state is shown, from vapor chamber simulations using the time-stepping analytical model and the finite-volume numerical model for Case \#2.

Figure 7. Comparison of pressure results from the vapor chamber simulations using the timestepping analytical model and the finite-volume numerical model for Case \#2. The relative pressure variation in the (a) wick and (b) vapor core are shown for the cross-sectional plane $\mathrm{y}=$ $27.5 \mathrm{~mm}$ at steady state.

Figure 8. Schematic diagram of the geometry and boundary conditions used to simulate multiple time-varying inputs with the time-stepping analytical vapor chamber model (thickness scaled $45 \times)$.

Figure 9. Time-stepping analytical solution of the (a) maximum temperature at the centers of the two heaters with time; (b) snapshot at $t=47 \mathrm{~s}$ showing the $3 \mathrm{D}$ contours of temperature in the vapor chamber (video in Supplementary Materials played at $5 \times$ real-time speed) and temperature contours on the condenser-side outer surface $(z=0.5 \mathrm{~mm})$ at (c) $t=33 \mathrm{~s}$ and (d) $t=66 \mathrm{~s}$. 


\section{List of Tables}

Table 1. Scales for the model variables.

Table 2. Properties of the working fluid, copper, and porous wick materials used in the vapor chamber simulations. Vapor properties are shown at a temperature of $300 \mathrm{~K}$. 
Table 1. Scales for the model variables.

\begin{tabular}{ll}
\hline \hline Variable & Scale \\
\hline$t$ & $\tau$ \\
$x$ & $L_{x}$ \\
$y$ & $L_{y}$ \\
$z$ in vapor core & $h_{\text {vap }}$ \\
$z$ in wick 1 & $h_{\text {wick }, 1}$ \\
$z$ in wick 2 & $h_{\text {wick,2 }}$ \\
$z$ in wall 1 & $h_{\text {wall, } 1}$ \\
$z$ in wall 2 & $h_{\text {wall,2 }}$ \\
$u$ in vapor core & $U_{\text {vap }}$ \\
$v$ in vapor core & $V_{\text {vap }}$ \\
$w$ in vapor core & $W_{\text {vap }}$ \\
$u$ in wick 1 & $U_{\text {wick, }, 1}$ \\
$v$ in wick 1 & $V_{\text {wick, } 1}$ \\
$w$ in wick 1 & $W_{\text {wick }, 1}$ \\
$u$ in wick 2 & $U_{\text {wick, }, 2}$ \\
$v$ in wick 2 & $V_{\text {wick,2 }}$ \\
$w$ in wick 2 & $W_{\text {wick }, 2}$ \\
\hline \hline
\end{tabular}


Table 2. Properties of the working fluid, copper, and porous wick materials used in the vapor chamber simulations. Vapor properties are shown at a temperature of $300 \mathrm{~K}$.

\begin{tabular}{l|r}
\hline \hline Property & \multicolumn{1}{|l}{ Value } \\
\hline Copper density $(\rho)$ & $8978 \mathrm{~kg} / \mathrm{m}^{3}$ \\
Water liquid density $(\rho)$ & $998.2 \mathrm{~kg} / \mathrm{m}^{3}$ \\
Water vapor density $(\rho)$ & $0.02 \mathrm{~kg} / \mathrm{m}^{3}$ \\
Copper thermal conductivity & $387.6 \mathrm{~W} / \mathrm{mK}$ \\
$\left(k_{\text {eff }}\right)$ & \\
Wick effective thermal & $40 \mathrm{~W} / \mathrm{mK}$ \\
conductivity $\left(k_{\text {eff }}\right)$ & \\
Water vapor thermal & $0.0187 \mathrm{~W} / \mathrm{mK}$ \\
conductivity $\left(k_{\text {eff }}\right)$ & $381 \mathrm{~J} / \mathrm{kgK}$ \\
Copper specific heat capacity & \\
$\left(C_{P}\right)$ & $4182 \mathrm{~J} / \mathrm{kgK}$ \\
Water liquid specific heat & $1889 \mathrm{~J} / \mathrm{kgK}$ \\
capacity $\left(C_{P}\right)$ & $1.79 \times 10^{-5} \mathrm{~Pa} \mathrm{~s}$ \\
Water vapor specific heat & $1 \times 10^{-3} \mathrm{~Pa} \mathrm{~s}$ \\
capacity $\left(C_{P}\right)$ & $4.46 \times 10^{6} \mathrm{~J} / \mathrm{kg}$ \\
Water liquid viscosity $(\mu)$ & $462 \mathrm{~J} / \mathrm{kgK}$ \\
Water vapor viscosity $(\mu)$ & \\
Enthalpy of vaporization $\left(h_{f g}\right)$ & $0.07 h_{\text {wick }}$ \\
Water vapor specific gas & \\
constant $(R)$ & $\varphi^{3} h_{\text {wick }}^{2}$ \\
Wick porosity $(\varphi)$ & $1350(1-\varphi)^{2}$ \\
Wick permeability $(K)$ & $2 \gamma$ \\
Capillary pressure $\left(P_{c a p}\right)$ & 2.6 \\
\hline \hline
\end{tabular}




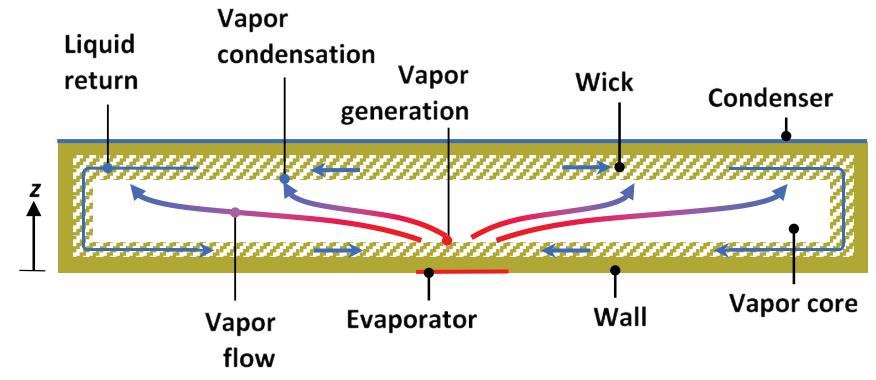

Figure 1. Cross-sectional view of vapor chamber operation that illustrates the key components and transport mechanisms. 

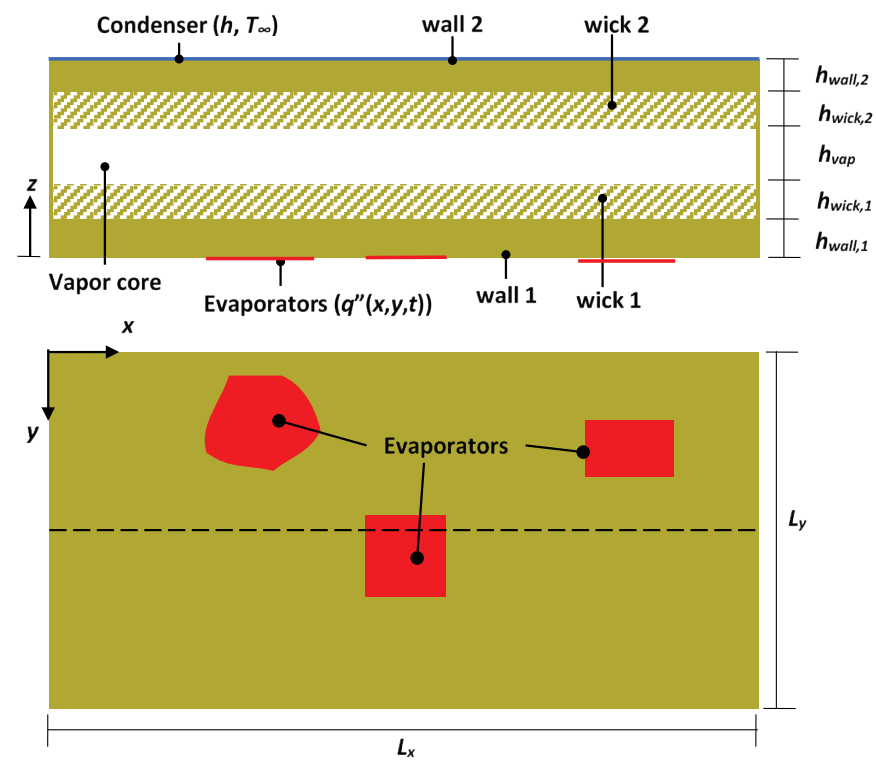

Figure 2. Vapor chamber transport model geometry and boundary conditions (cross-section and bottom views). 


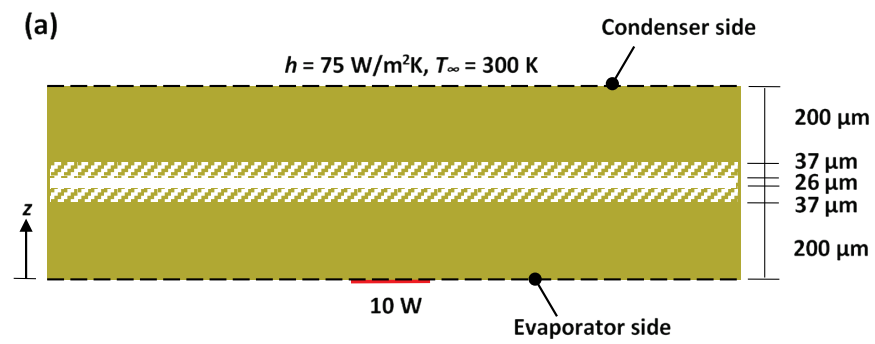

(b)
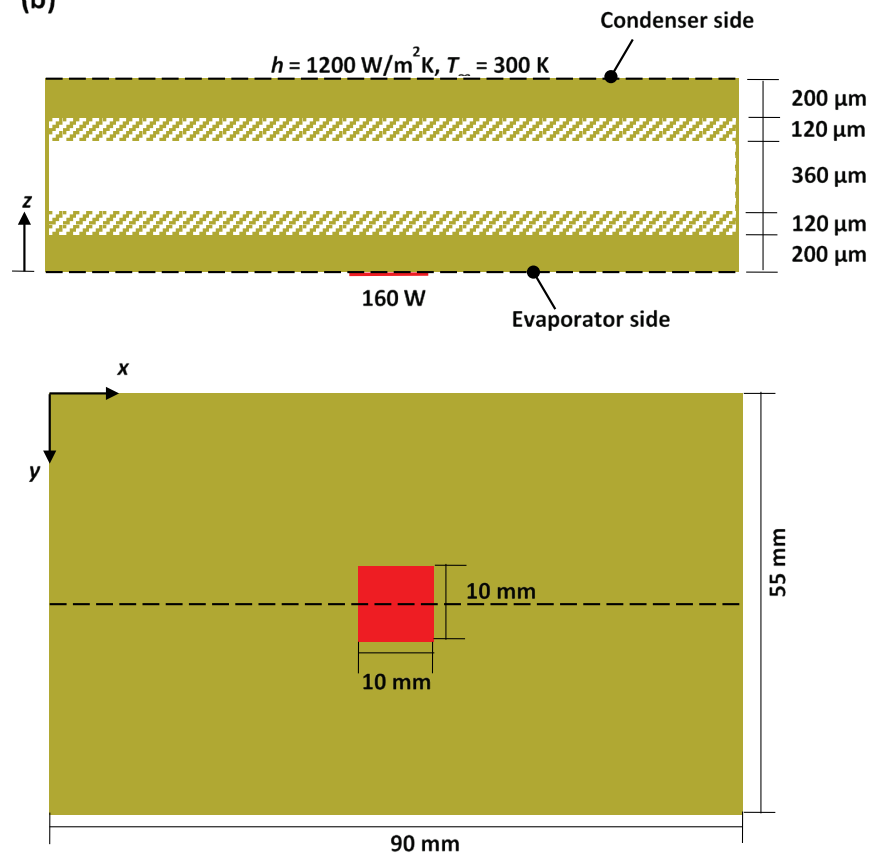

Figure 3. Schematic diagram of the simulated geometry and boundary conditions used to validate the time-stepping analytical vapor chamber model, showing a bottom view at the bottom and cross-section at the top for (a) Case \#1 (thickness scaled 50×), and (b) Case \#2 (thickness scaled $25 \times)$. 


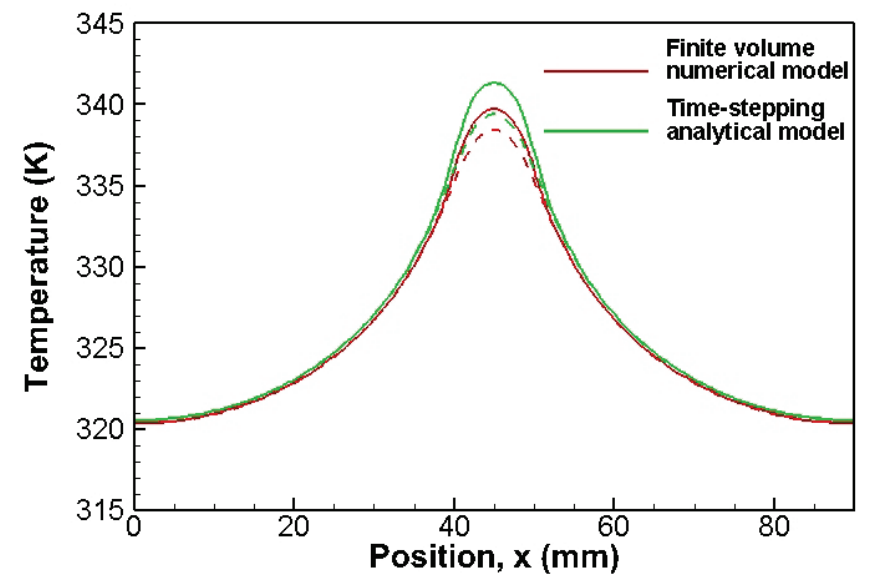

(a)

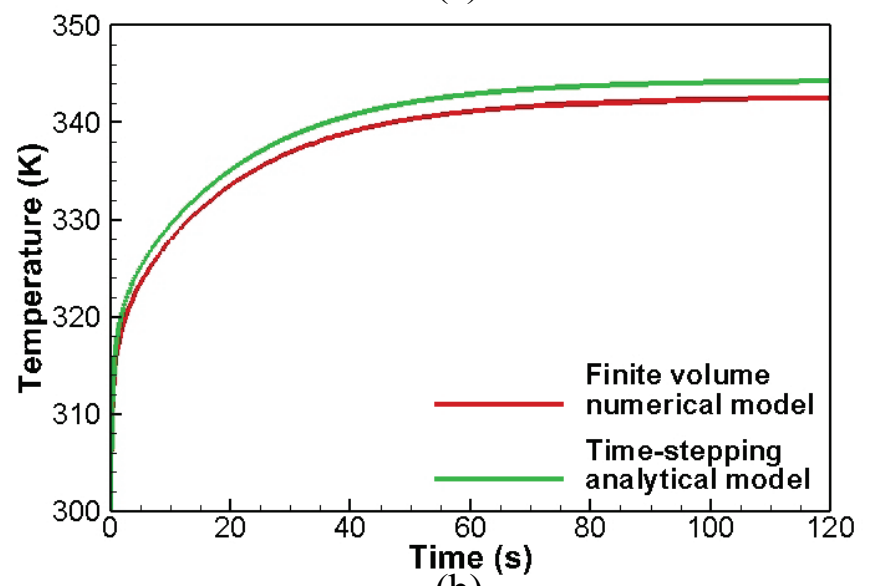

(b)

Figure 4. Comparison of temperature results from vapor chamber simulations using the timestepping analytical model and the finite-volume numerical model for Case \#1. (a) The temperature profile is shown along the evaporator-side outer surface (solid lines; $z=0 \mathrm{~mm}, y=$ $27.5 \mathrm{~mm}$ ) and the condenser-side outer surface (dashed lines; $z=0.5 \mathrm{~mm}, y=27.5 \mathrm{~mm}$ ), at $t=$ $44.5 \mathrm{~s}$. (b) The variation of the maximum temperature in the vapor chamber (at $z=0 \mathrm{~mm}, x=45$ $\mathrm{mm}, y=27.5 \mathrm{~mm}$ ) with time predicted by the two models is compared. 


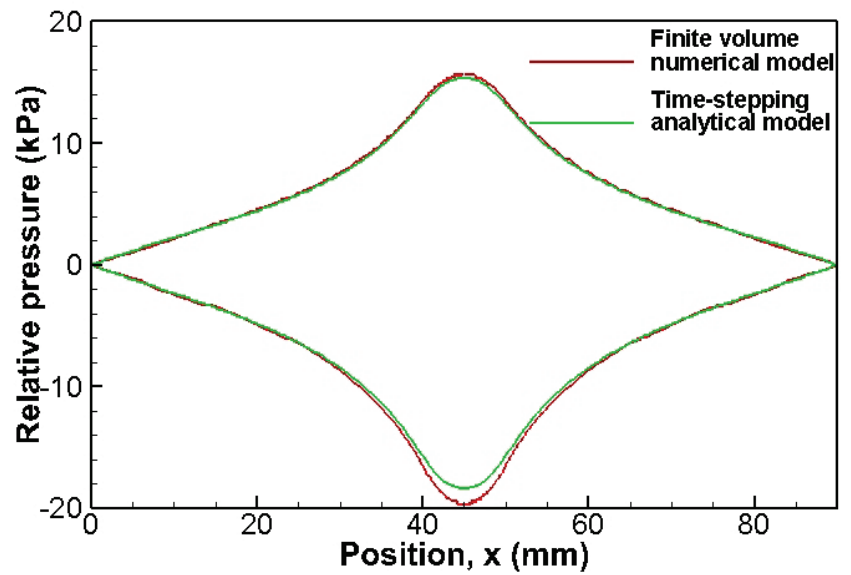

(a)

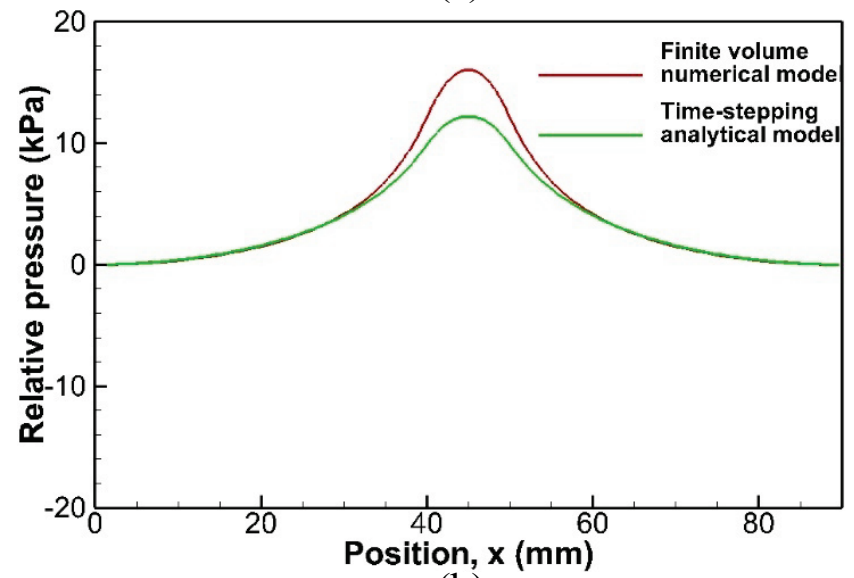

(b)

Figure 5. Comparison of pressure results from the vapor chamber simulations using the timestepping analytical model and the finite-volume numerical model for Case \#1. The relative pressure variation in the (a) wick and (b) vapor core are shown for the cross-sectional plane $y=$ $27.5 \mathrm{~mm}$ at $t=44.5 \mathrm{~s}$. 


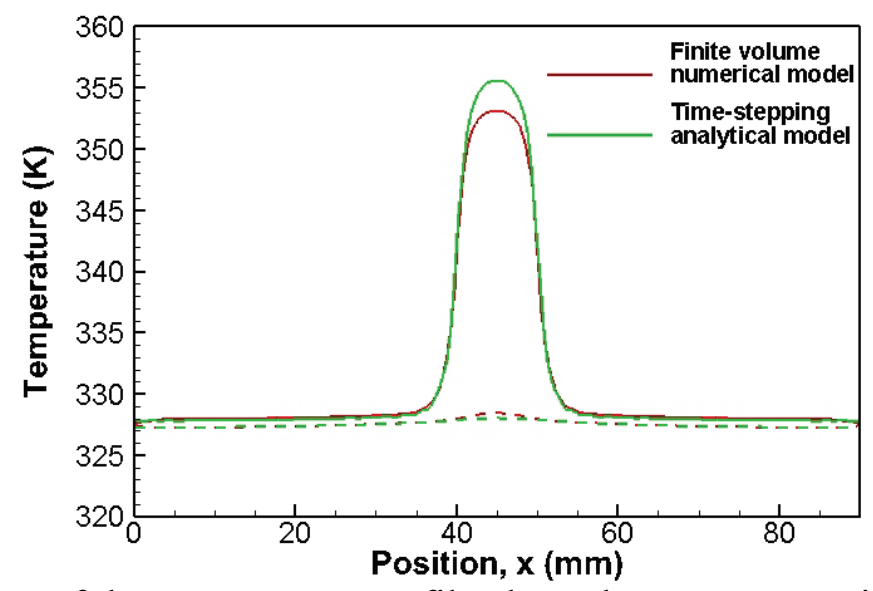

Figure 6. Comparison of the temperature profile along the evaporator-side outer surface (solid lines; $z=0 \mathrm{~mm}, y=27.5 \mathrm{~mm}$ ) and the condenser-side outer surface (dashed lines; $z=1 \mathrm{~mm}, y=$ $27.5 \mathrm{~mm}$ ), at steady-state is shown, from vapor chamber simulations using the time-stepping analytical model and the finite-volume numerical model for Case \#2. 


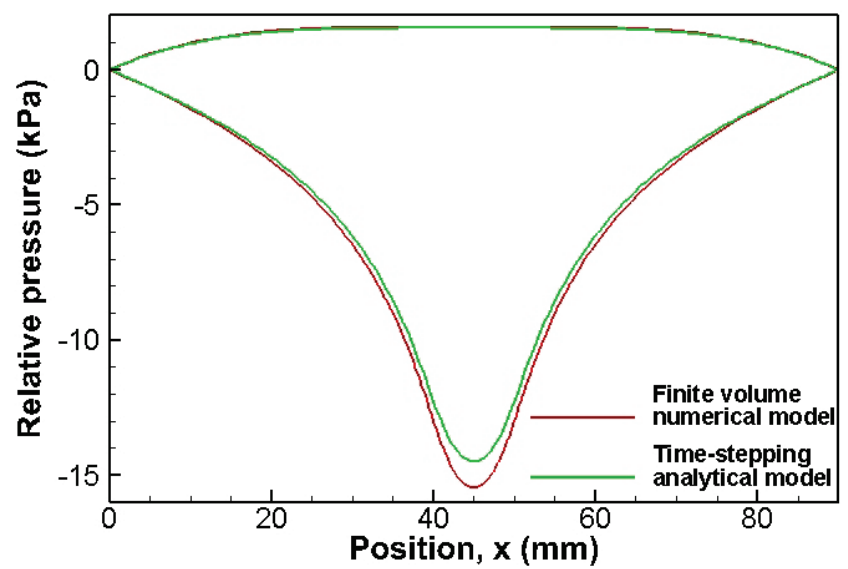

(a)

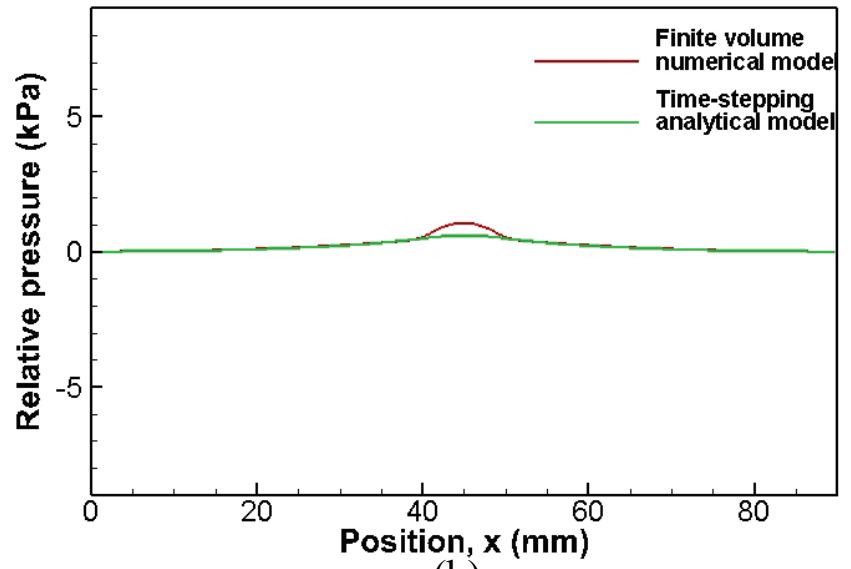

(b)

Figure 7. Comparison of pressure results from the vapor chamber simulations using the timestepping analytical model and the finite-volume numerical model for Case \#2. The relative pressure variation in the (a) wick and (b) vapor core are shown for the cross-sectional plane $y=$ $27.5 \mathrm{~mm}$ at steady state. 


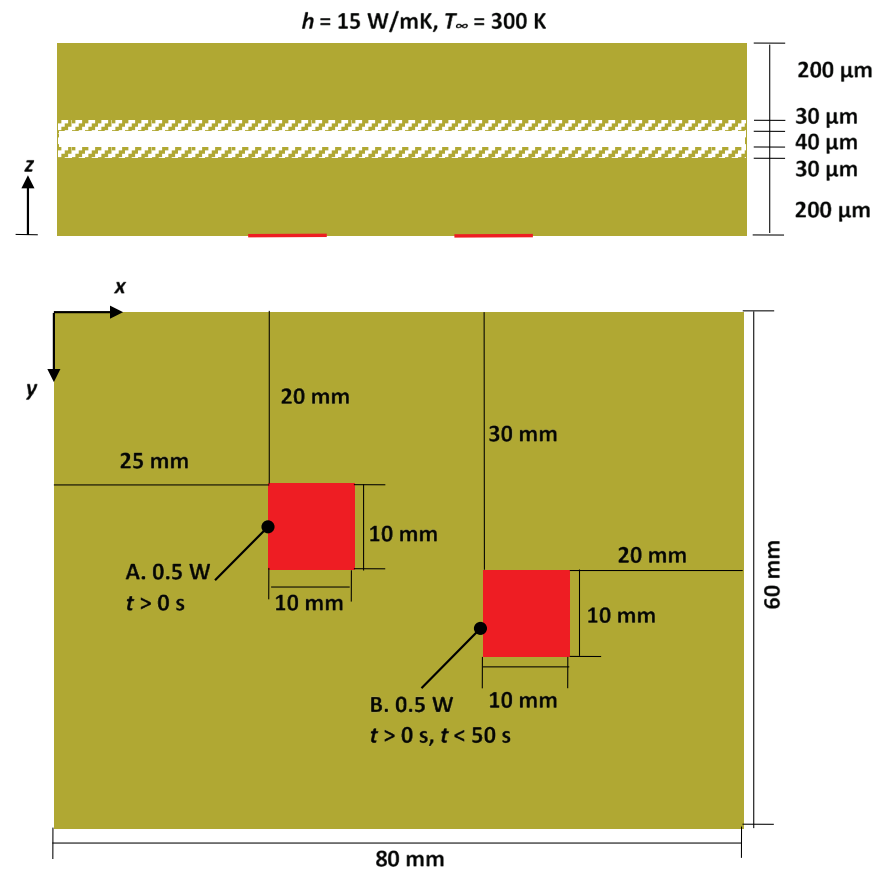

Figure 8. Schematic diagram of the geometry and boundary conditions used to simulate multiple time-varying inputs with the time-stepping analytical vapor chamber model (thickness scaled $45 \times)$. 


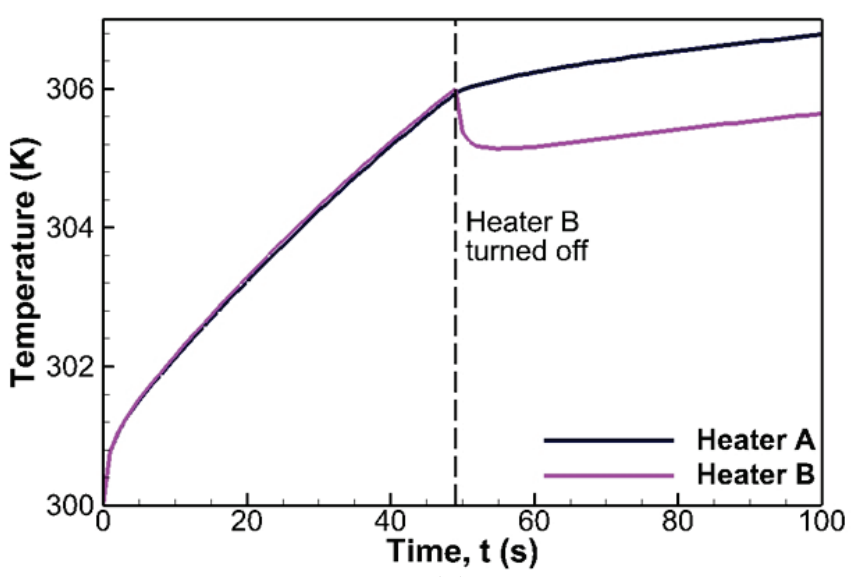

(a)

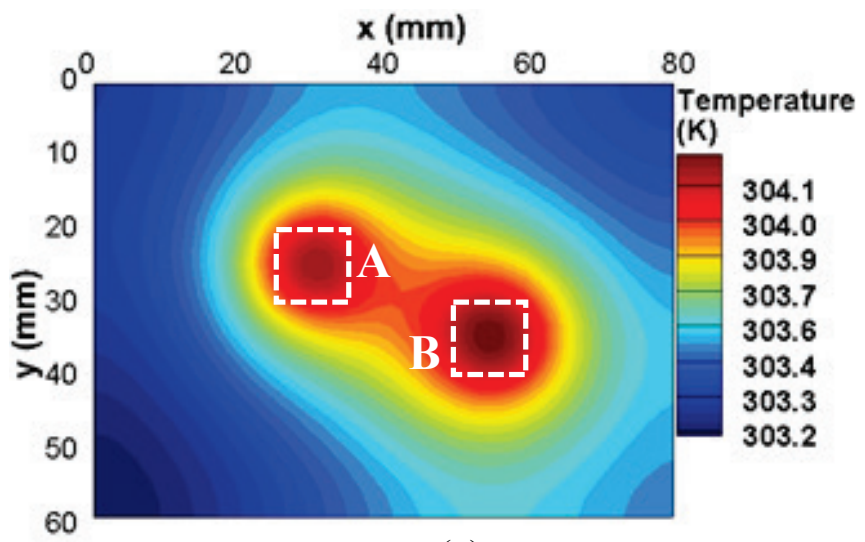

(c)

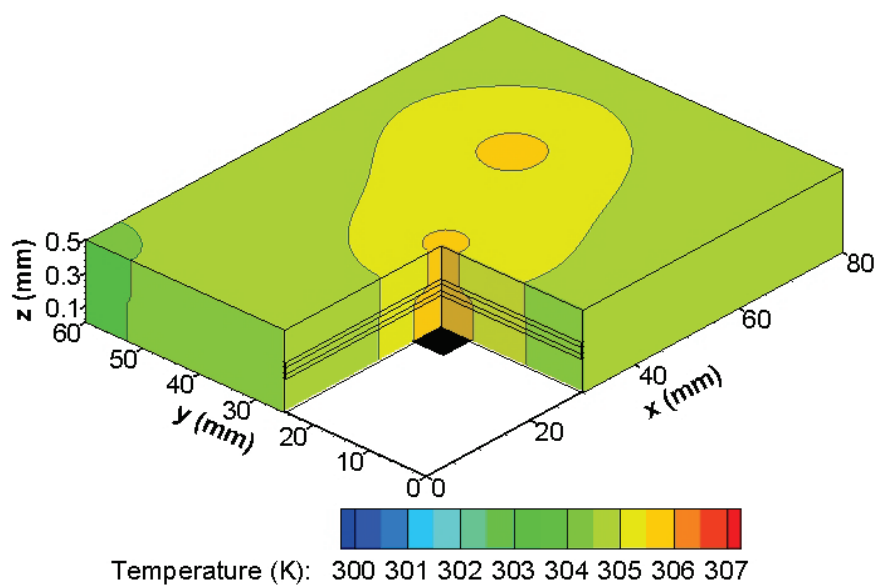

(b)

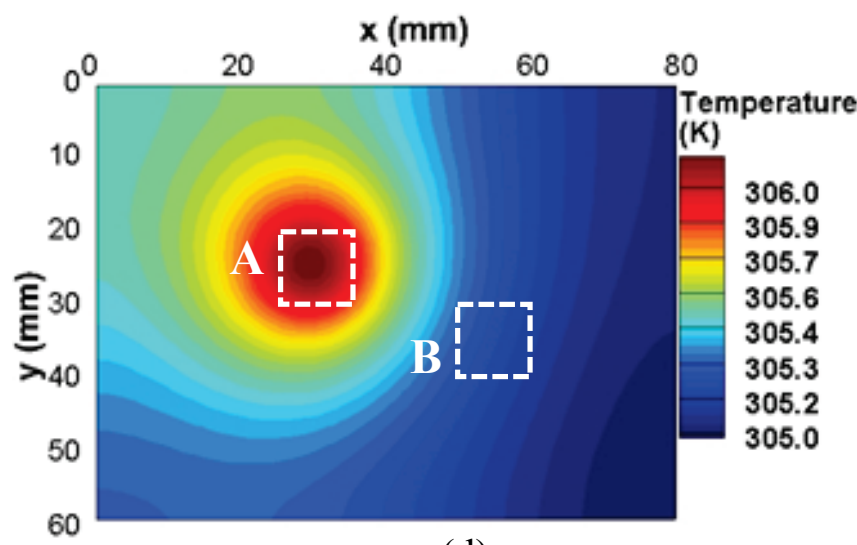

(d)

Figure 9. Time-stepping analytical solution of the (a) maximum temperature at the centers of the two heaters with time; (b) snapshot at $t=47 \mathrm{~s}$ showing the $3 \mathrm{D}$ contours of temperature in the vapor chamber, with $z$-direction scaled $20 \times x$ (video in Supplementary Materials played at $5 \times$ real-time speed) and temperature contours on the condenser-side outer surface $(z=0.5 \mathrm{~mm})$ at (c) $t=33 \mathrm{~s}$ and (d) $t=66 \mathrm{~s}$. 